Article

\title{
Towards a Sensitivity Analysis in Seismic Risk with Probabilistic Building Exposure Models: An Application in Valparaíso, Chile Using Ancillary Open-Source Data and Parametric Ground Motions
}

\author{
Juan Camilo Gómez Zapata ${ }^{1,2, * \mathbb{D}}$, Raquel Zafrir ${ }^{1,3,4,+}$, Massimiliano Pittore ${ }^{1,5}$ and Yvonne Merino ${ }^{6,7}$ (D) \\ check for \\ updates \\ 1 Seismic Hazard and Risk Dynamics, Helmholtz Centre Potsdam GFZ German Research Centre for \\ Geosciences, 14473 Potsdam, Germany; rmzafrir@gmail.com (R.Z.); massimiliano.pittore@eurac.edu (M.P.) \\ 2 Institute for Geosciences, University of Potsdam, 14469 Potsdam, Germany \\ 3 Department of Geomatics, Computer Science and Mathematics, \\ Stuttgart Technology University of Applied Sciences, 70174 Stuttgart, Germany \\ 4 INSUCO, Quito 170102, Ecuador \\ 5 EURAC Research, 39100 Bolzano, Italy \\ 6 Department of Structural and Geotechnical Engineering, Pontificia Universidad Católica de Chile, \\ Vicuña Mackenna 4860, Santiago 7820436, Chile; ymerino@uc.cl \\ 7 National Research Center for Integrated Natural Disaster Management (CIGIDEN), Vicuña Mackenna 4860, \\ Santiago 7820436, Chile \\ * Correspondence: jcgomez@gfz-potsdam.de \\ + Affiliations 1 and 3 are the former affiliation.
}

Citation: Gómez Zapata, J.C.; Zafrir, R.; Pittore, M.; Merino, Y. Towards a Sensitivity Analysis in Seismic Risk with Probabilistic Building Exposure Models: An Application in Valparaíso, Chile Using Ancillary Open-Source Data and Parametric Ground Motions. ISPRS Int. J. Geo-Inf. 2022, 11, 113. https:// doi.org/10.3390/ijgi11020113

Academic Editors: Hiroyuki Miura, Masashi Matsuoka,

Yoshihisa Maruyama and

Wolfgang Kainz

Received: 22 December 2021

Accepted: 30 January 2022

Published: 6 February 2022

Publisher's Note: MDPI stays neutral with regard to jurisdictional claims in published maps and institutional affiliations.

Copyright: (c) 2022 by the authors Licensee MDPI, Basel, Switzerland. This article is an open access article distributed under the terms and conditions of the Creative Commons Attribution (CC BY) license (https:// creativecommons.org/licenses/by/ $4.0 /)$

\begin{abstract}
Efforts have been made in the past to enhance building exposure models on a regional scale with increasing spatial resolutions by integrating different data sources. This work follows a similar path and focuses on the downscaling of the existing SARA exposure model that was proposed for the residential building stock of the communes of Valparaíso and Viña del Mar (Chile). Although this model allowed great progress in harmonising building classes and characterising their differential physical vulnerabilities, it is now outdated, and in any case, it is spatially aggregated over large administrative units. Hence, to more accurately consider the impact of future earthquakes on these cities, it is necessary to employ more reliable exposure models. For such a purpose, we propose updating this existing model through a Bayesian approach by integrating ancillary data that has been made increasingly available from Volunteering Geo-Information (VGI) activities. Its spatial representation is also optimised in higher resolution aggregation units that avoid the inconvenience of having incomplete building-by-building footprints. A worst-case earthquake scenario is presented to calculate direct economic losses and highlight the degree of uncertainty imposed by exposure models in comparison with other parameters used to generate the seismic ground motions within a sensitivity analysis. This example study shows the great potential of using increasingly available VGI to update worldwide building exposure models as well as its importance in scenario-based seismic risk assessment.
\end{abstract}

Keywords: exposure; buildings; Bayesian model; downscaling; OpenStreetMap; ground motion fields; sensitivity; earthquake; vulnerability; risk

\section{Introduction}

Exposure refers to the presence of people, livelihoods, species or ecosystems, services, infrastructure, or economic and social assets in places and settings that could be adversely affected by hazardous events [1]. Therefore, to describe their differential levels of propensity or predisposition to be affected, various methodologies are used to assess specific types of vulnerabilities (e.g., social, physical, or systemic). In the case of evaluating the physical vulnerability of a building stock exposed to earthquakes (i.e., forecasting the 
likely distributions of damages and direct financial losses), it is necessary, among other actions, to investigate the expected seismic ground motions as well as the composition of the building portfolio. The latter involves classifying buildings into mutually exclusive collective-exhaustive building classes to form the so-called building exposure model. Each class describes a distinctive physical vulnerability to ground shaking, depending on its physical properties or attributes [2]. Typically, the uncertainty in the exposure component has received less attention than other parts of the seismic risk chain (i.e., hazard and vulnerability) [3]. Notably, only a few recent studies have indicated that its investigation would benefit from increased research $[4,5]$. In this context, the concepts of intra-building and inter-building-variabilities were formally introduced in [6]. The first involves the variations at the individual level, whilst the second refers to the differences between various units belonging to the same class. Both types of variabilities are embedded in the problem of classifying a building stock (sometimes very heterogeneous) into a limited set of subjectively proposed typologies. Nonetheless, it is important to consider that, due to the scope of using the exposure model as input for risk estimations, the complexity in the classification of buildings should not increase beyond the available set of fragility functions for generic typologies designed for specific areas $[7,8]$.

Top-down studies (i.e., desktop studies) that rely on expert-based assumptions and census data analyses are, to date, the most widely used approaches to represent the composition of large-scale exposure models over administrative boundaries. These activities foresee the exposure model as a screenshot for a fixed time and with a unique composition while establishing both the classes and their respective proportions. Following that approach, global exposure models have been proposed [9-11]. Some of them have made use of census co-variants to infer building classes through so-called "mapping schemes" (e.g., [12]). However, since census data are available for dwellings and not buildings, further assumptions on the dwelling-to-building ratios are employed by that method (e.g., [13]). Consequently, distinct expert-based assumptions can lead to contrasting models for the same study area (e.g., [14,15]). Furthermore, recent paradigms in exposure modelling have increasingly demonstrated the relevance of counting with spatial and temporal projections to track the evolution and dynamics of the built environment (e.g., $[16,17])$ as well as count with efficient spatial aggregation techniques [18].

In order to validate the assumptions of the aforementioned top-down approaches about the portfolio composition and to identify zones with similar or contrasting physical vulnerabilities, it is required to consider these with bottom-up perspectives (i.e., in situ or remote data collection) [19]. This is especially relevant when some building attributes that drive their seismic vulnerability, such as structural irregularities [20], are neither randomly nor homogenously spatially distributed throughout the area of interest [21]. In this framework, emerging technologies have been proven to be useful to classify large-scale building stocks. For instance, we can mention the use of machine learning techniques over local datasets [22], feature extraction from remote sensing (e.g., [23,24]), façade image reconnaissance analyses (e.g., [25,26]), integrating multi-source information from remote sensing and surveys [27], and downscaling existing models based on remote sensing products being used as ancillary data (e.g., $[28,29])$. Moreover, methods to design focused surveys for data collection were also proposed (e.g., [30]). These types of survey designs are useful when the full enumeration of entire building stocks is a highly resource-intensive task [31]. During such inspections, instead of "labelling" buildings as certain typologies, their attributes can also be collected in terms of well-known taxonomies (e.g., [32]). Based on the former idea, Pittore et al. (2018) [33] proposed assessing the degree of compatibility between predefined building classes and inspected building attributes. This procedure offered not only a more transparent classification system (e.g., [34]) but also the ability to configure other hazard-oriented vulnerability schemes (i.e., they are applied not only to earthquakes, such as in [35]).

Some recent studies have shown that carefully inspecting a smaller sample (representative subset) is instrumental to inferring the seismic vulnerability of a larger area 
(e.g., [36-38]). However, the integration of such bottom-up data collection within a robust statistical framework is a relatively new type of approach that was first considered in [39]. That study proposed a Bayesian method to probabilistically forecast the composition of the building stock of a given area through expert-based priors (about the expected proportions per class) that are increasingly superseded by the real data that are continuously captured during surveys and used to configure the likelihood term. Then, the resulting posterior distribution was assumed to provide the exposure composition (i.e., proportions per class). It is worth exploring the capabilities of integrating freely available crowdsourcing data sources (e.g., OpenStreetMap or OSM) into such probabilistic exposure models. Although this type of volunteer-acquired data lacks standardised formats and completeness [40,41], the data offer valuable information on the spatial location of certain attributes without necessarily performing time-consuming in situ data collection. They have proved useful for acquiring socio-economic indicators [42]), assessing the physical vulnerability of local buildings to earthquakes (e.g., [43-45]) and floods (e.g., [46,47]), and in global exposure initiatives [48,49].

Throughout this work, we rely on the results first outlined in [28,50], which formally presented a Bayesian approach for building exposure modelling to then achieve the following specific objectives:

- Presenting the capabilities of integrating a freely available dataset gathered from VGI (without having to inspect individual buildings) to derive a probabilistic exposure model for residential buildings in Valparaíso and Viña del Mar (Chile), based on the inferred building footprint area for certain typologies.

- In addition to better characterising the building composition, this approach has improved its spatial representation by downscaling a coarser existing exposure model onto higher-resolution regular grids. Then, a large magnitude earthquake scenario can be defined, and a related set of exhaustive seismic ground motion fields through the variation of some of its driving parameters can be constructed.

- Use the former set of groung motions along with the three exposure models as inputs to independently calculate the direct economic losses that are expected from the building portfolio subjected to such a worst-case earthquake scenario. This vulnerability assessment allows us to propagate and compare the uncertainties embedded in the exposure models with respect to the parameters used to constrain the seismic ground motions.

\section{Context of the Study Area}

The study area included the communes of Valparaíso and Viña del Mar (Chile), which have 295,113 and 326,759 inhabitants, respectively (2017) [51], forming the second-largest urban area of the country after Santiago de Chile. The area also houses the main port of the country, and therefore its physical security is vital for the national economy. For simplicity, both communes are referred to as "Valparaíso" hereafter. In Figure 1, we show the location of the study area within central Chile, as well as within the first, second, and third administrative divisions (i.e., region, province, and commune, respectively).

Valparaíso has been afflicted by powerful historical earthquakes. The 1730 event with an inferred magnitude of $\mathrm{Mw}$ 9.1-9.3 is recognised as one of the largest earthquakes to occur in Chile in written history [52]. Another destructive earthquake with an inferred moment magnitude Mw 8.0-8.2 occurred in 1906 and caused significant damage [53]. Since then, 12 earthquakes with a macroseismic intensity greater than VII (Mercalli scale) have affected this area [54]. It is remarkable the $1985 \mathrm{Mw} 7.8$ event that destroyed 140,000 dwellings, left 950,000 persons homeless and caused losses of about USD 1.8 billion [55]. The last one out of those 12 events was the $2010 \mathrm{Mw} 8.8$ earthquake, which caused structural damages to buildings in Viña del Mar [56] and impacted upon the labour markets [57]. More recently, the $2017 \mathrm{Mw} 6.9$ event was felt in the city with a lower intensity [58]. To forecast the expected damage distributions and losses resulting from future earthquake scenarios affecting the area of interest, in addition to investigating the likely seismic ground 
motions, it was also necessary to constrain the spatial distribution and composition of the exposed building stock and their associated physical vulnerabilities.

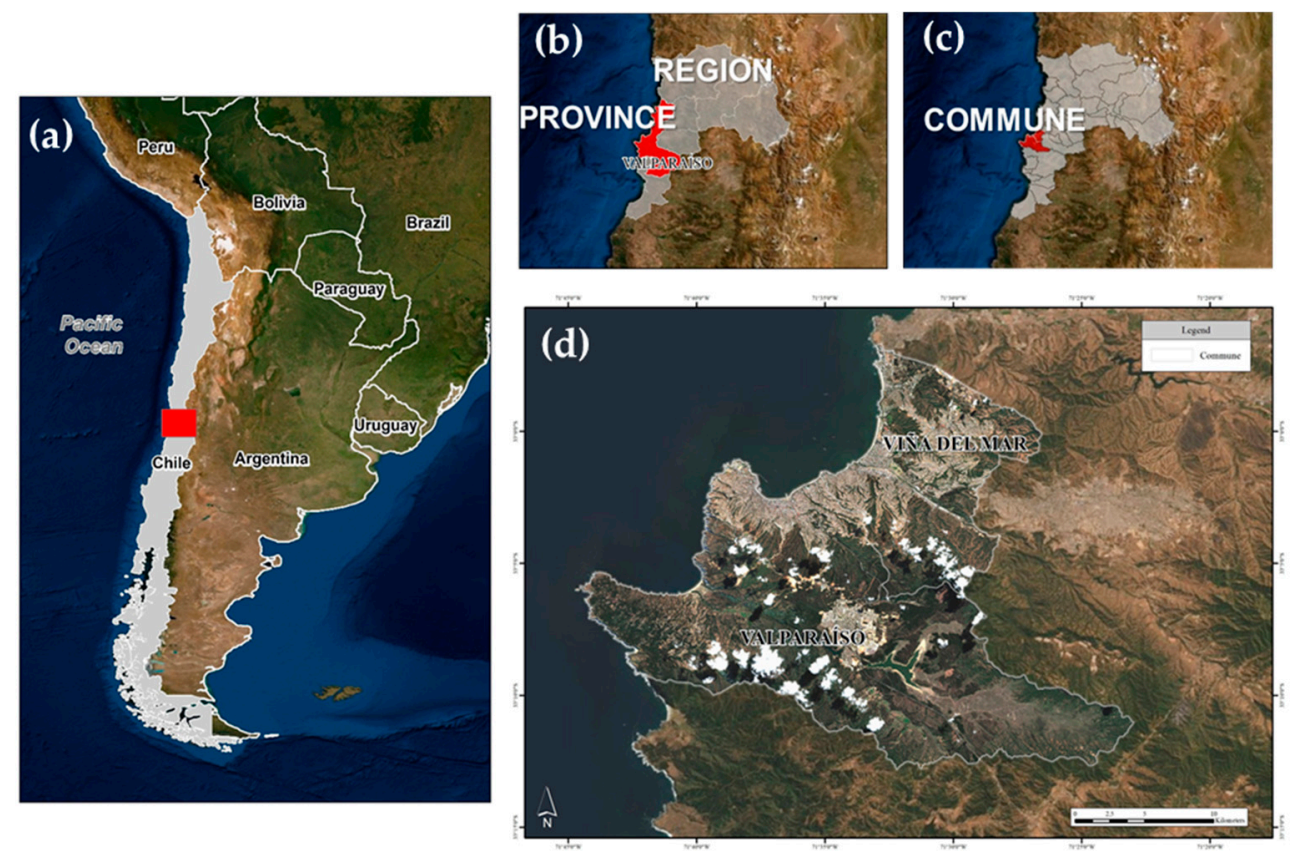

Figure 1. Location of the study area within (a) Chile, (b) the Valparaíso region (grey) and Valparaíso province (red), and (c) communes of Valparaíso and Viña del Mar. (d) Detailed image of the two communes, showing Sentinel-2 images for 21 September 2019 (downloaded from the Copernicus Open Access Hub of the European Space Agency (ESA)). Map data @ Google Earth 2019. Edited from $[50,59]$.

Valparaíso has a very diverse building portfolio [54], and notably, its historic quarter was declared a World Heritage Site by UNESCO in 2003 after distinguishing its varied urban fabric [60]. Few studies have reported on building exposure models for Valparaíso. The South American Risk Assessment (SARA) project harmonised the residential building through a top-down approach [61]. It reached its highest spatial resolution at their third administrative division (i.e., commune in Chile). This means that, for the area of our interest, this dataset was aggregated onto two large geo-cells. On the other hand, the authors of [62] investigated the use of bottom-up approaches, such as the integration between OSM training segments and remote sensing satellite imagery for exposure modelling in Valparaíso. That study provided a land use map and a possible range of building units.

More recently, and following the Bayesian method outlined in [39], residential building exposure models of Valparaíso were modelled in [59]. These authors made use of existing expert-based prior assumptions along with only a few ( 600) remote building-by-building surveys to ultimately create various posterior distributions that emulated synthetic building portfolios whose variable compositions depended on the relative degree of knowledge of the true proportions associated with each class. Thereby, the 2020-based population counts from the remote sensing data [63] were used to spatially allocate each synthetic portfolio according to the nighttime residents assumed for each class. The latter was performed over the same resolution (i.e., $\sim 1 \mathrm{~km}$ regular grid) through dasymetric disaggregation. The latter study did not provide a unique or better estimate of the exposure composition, but it rather presented how the range of variations of building counts and class proportions can be successfully diminished to consequently reduce the epistemic uncertainty in scenario-based loss estimates. 


\section{Materials and Methods}

We first present the derivation of a land use map recently available for the study area. Later, we introduce some generalities of the building exposure model along with certain assumptions over the composition of the residential building stock of Valparaíso. We then recall a Bayesian method to update the initial assumptions through the integration of the available OSM building footprints to ultimately derive a probabilistic exposure model along with two intermediate exposure models. Finally, the physical vulnerability of the residential building stock and its associated direct economic losses stock are calculated for a selected earthquake scenario. This allows us to explore some differences and epistemic uncertainties imposed by the exposure models available for Valparaíso in earthquake loss models. This process, outlined in Figure 2, will be presented in the following sections.

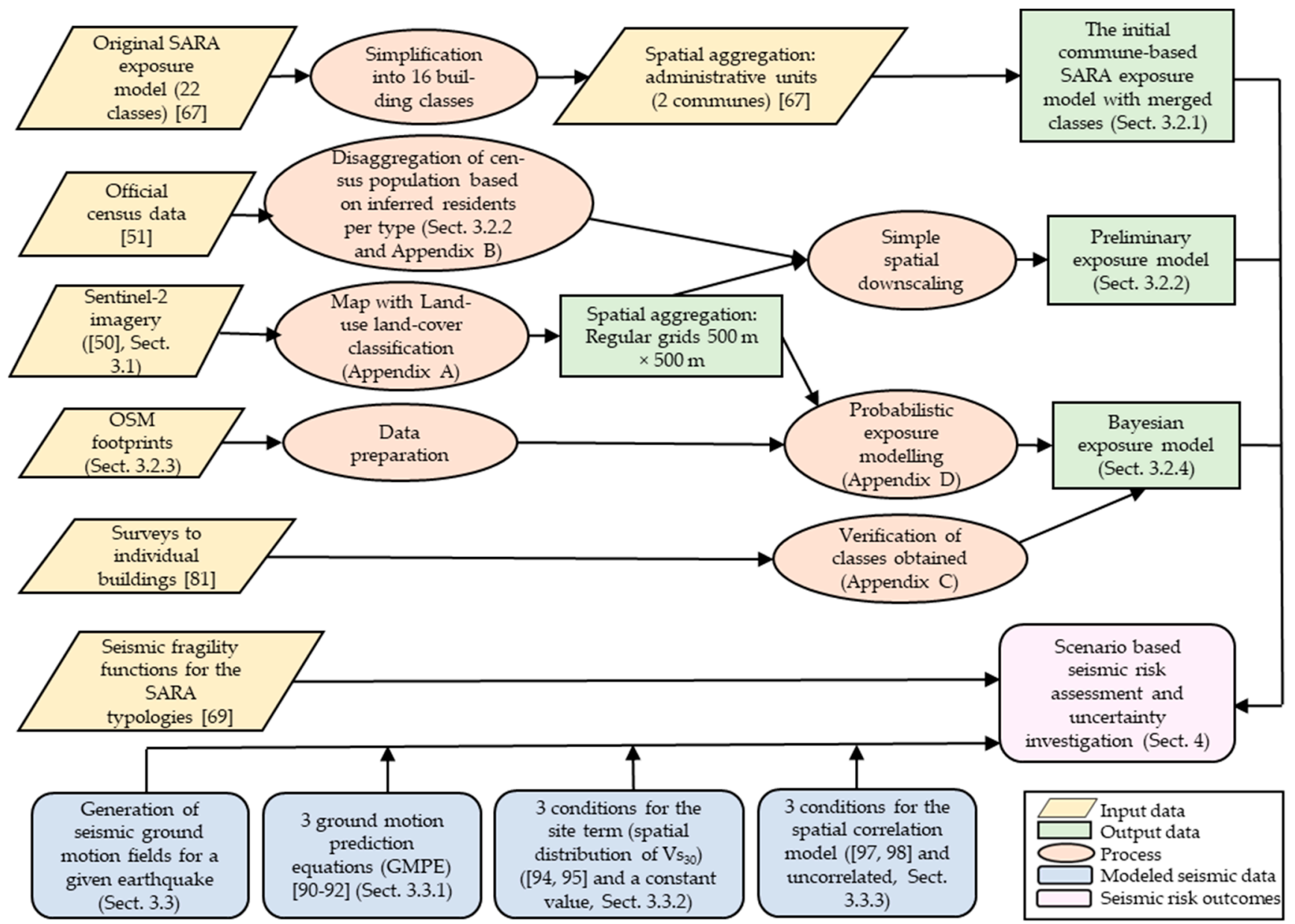

Figure 2. Flowchart outlining the input data gathered, the processes, and the three resulting residential building exposure models for Valparaíso (Chile) we will be presenting throughout this study. These exposure models, together with the parametric ground motions, are used as inputs for the sensitivity analysis in scenario-based seismic risk in the last stage of this study.

\subsection{Delimitation of the Urban Area and Some Initial Features}

A supervised classification using Sentinel-2 imagery (21 September 2019 (Figure 1d) at level tier C1 [64]) was carried out in [50] for the study area, deriving a land use classification by making use of the ERDAS software [65] to have a clearer delimitation of the built-up area in Valparaíso. The resultant land use classification is presented in Figure A1 (Appendix A). Although this product has not had as many signatures as other more exhaustive models (e.g., [66]), it has still allowed us to better relate the built-up area for a continuous urban extent to meaningful geographical entities. 


\subsection{Building Exposure and Vulnerability Models for Valparaíso}

Three exposure models for residential buildings are presented hereafter, along with a brief description of some ancillary data used to constrain the third (Bayesian) one.

\subsubsection{The Initial Commune-Based SARA Exposure Model with Merged Classes}

We assume that the residential building stock of Valparaíso and Viña del Mar can be fully represented in terms of the typologies originally proposed by the SARA project [67]. That project established the composition of the residential building stocks of the Andean countries based on expert elicitation to design "mapping schemes". These schemes define the relationship between a few country-specific census descriptors (e.g., façades and floor material) and certain vulnerability classes for dwellings. Notably, the Chilean census employed by the authors dates back to 2002 [68]. Therefore, the original SARA exposure model presented the composition of the residential building stock of Valparaíso for that year. Although the typologies might not drastically change, it is highly likely that their associated building counts will considerably differ from the current context of the city.

The SARA building classes are described in terms of certain attributes contained in the GEM v.2.0 building taxonomy [32], namely the type and material of the lateral loadresisting system (LLRS), height, and rarely the ductility type and material technology. Descriptions of these attributes are provided at https://taxonomy.openquake.org/ (accessed date: 21 December 2021). For each dwelling class, the authors proposed "dwelling fractions" (i.e., dwellings per building type) to obtain the number of buildings. For Valparaíso, the SARA project proposed 22 classes [67], while we reduced this to 16 (Figure 3). The assumptions considered to reduce the number of typologies were as follows:

- We did not consider the class "UNK" (unknown) because it lacked observable attributes. Its proportion $(\sim 10 \%)$ was redistributed to the other classes.

- We combined five pairs of classes into a more generic enclosing typology that had a similar taxonomic description and only differed in their storey ranges. These were ER-ETR-H1 within ER-ETR-H1-2, MCF-DNO-H1 within MCF-DNO-H1-3, MUR-ADOH1 within MUR-ADO-H1-2, W-WLI-H1 within W-WLI-H1-3, and W-WS-H1 within W-WS-H1-2.

The 16 resulting classes had differential seismic vulnerabilities, as expressed by their corresponding fragility functions reported in [69] (Figure 4). Table 1 provides further information per typology. The average footprint areas per class $\left(\mathrm{Ft} . / \mathrm{bdg} .\left(\mathrm{m}^{2}\right)\right)$ were derived from the "reference average area per dwelling" values as a function of the construction quality reported in [67] for Chile. They were $70 \mathrm{~m}^{2}, 80 \mathrm{~m}^{2}$, and $70 \mathrm{~m}^{2}$ for the upper, middle, and lower construction quality, respectively. Aligned with the construction practices in Valparaíso and with the last two Chilean seismic codes (NCh433 Of.72, [70] and NCh433 Of.96 [71]), the earthen, masonry, and non-ductile (excluding RC) types were assumed to have a lower construction quality, wooden and non-ductile RC classes had a middle one, and ductile RC classes had an upper quality. The values of such categorizations were multiplied by the number of dwellings per class and then divided by their respective average numbers of storeys. Finally, they were divided by the number of buildings per class to obtain the inferred building footprint area per typology. This procedure is illustrated in Table A1. 

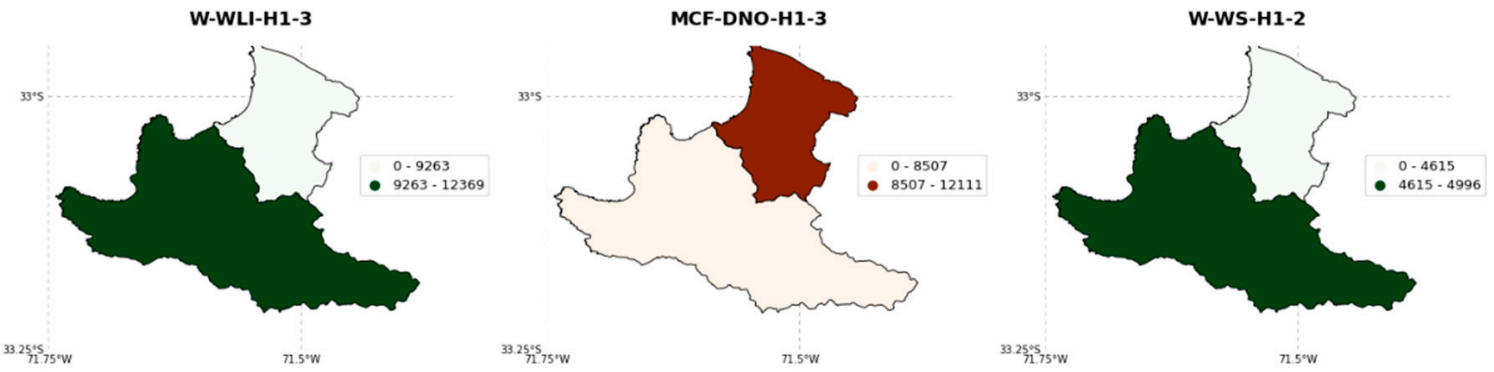

$332551.75 \% \mathrm{~W}$

$71.5^{\circ} \mathrm{W}$

$33.251 .75^{\circ} \mathrm{W}$
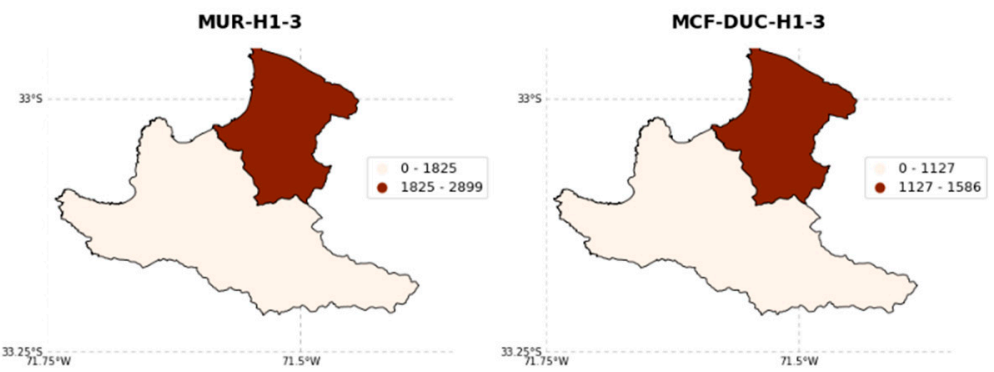

$33.255 .5755 \mathrm{w}$

$7.5^{\circ} \mathrm{W}$
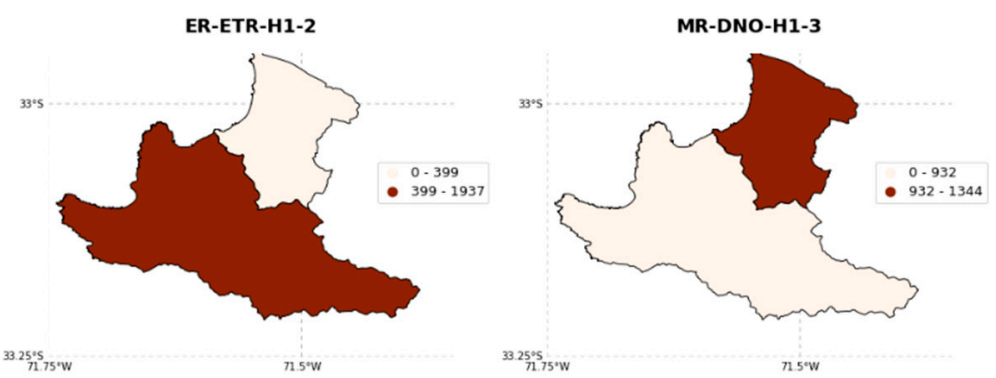

$33254.55 \cdot 7$

n. 5 w
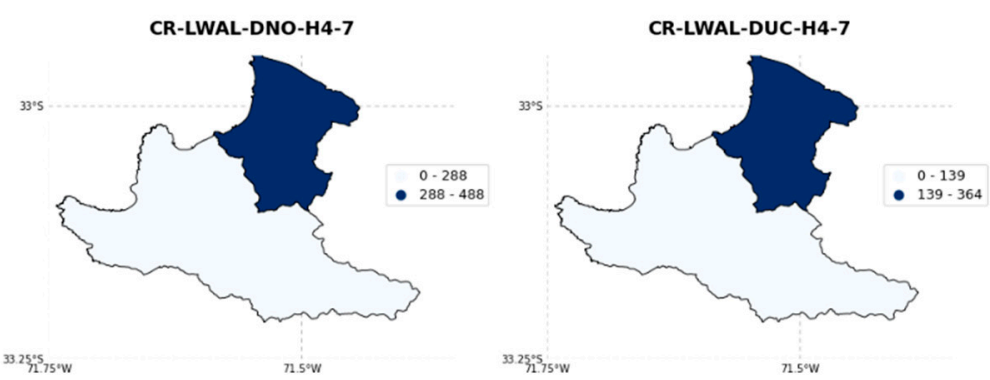

$3327^{5} 1^{5} 77^{\circ} \mathrm{W}$

$715^{\circ} \mathrm{W}$
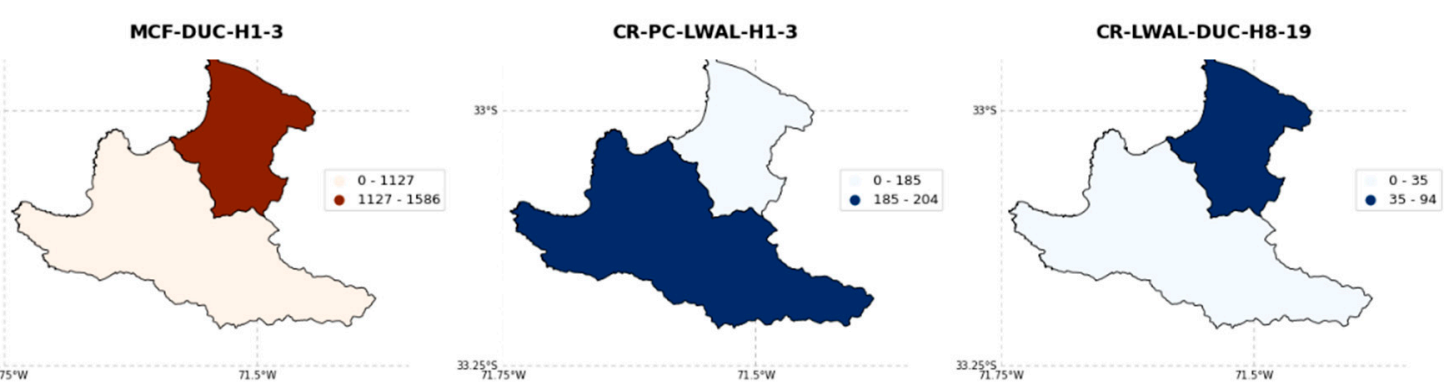

Figure 3. Building counts at the commune level for 15 SARA building classes (after having combined similar typologies (Section 3.2.1)). The colour scale represents the material type (green = wooden; orange $=$ masonry; blue $=$ reinforced concrete) . 

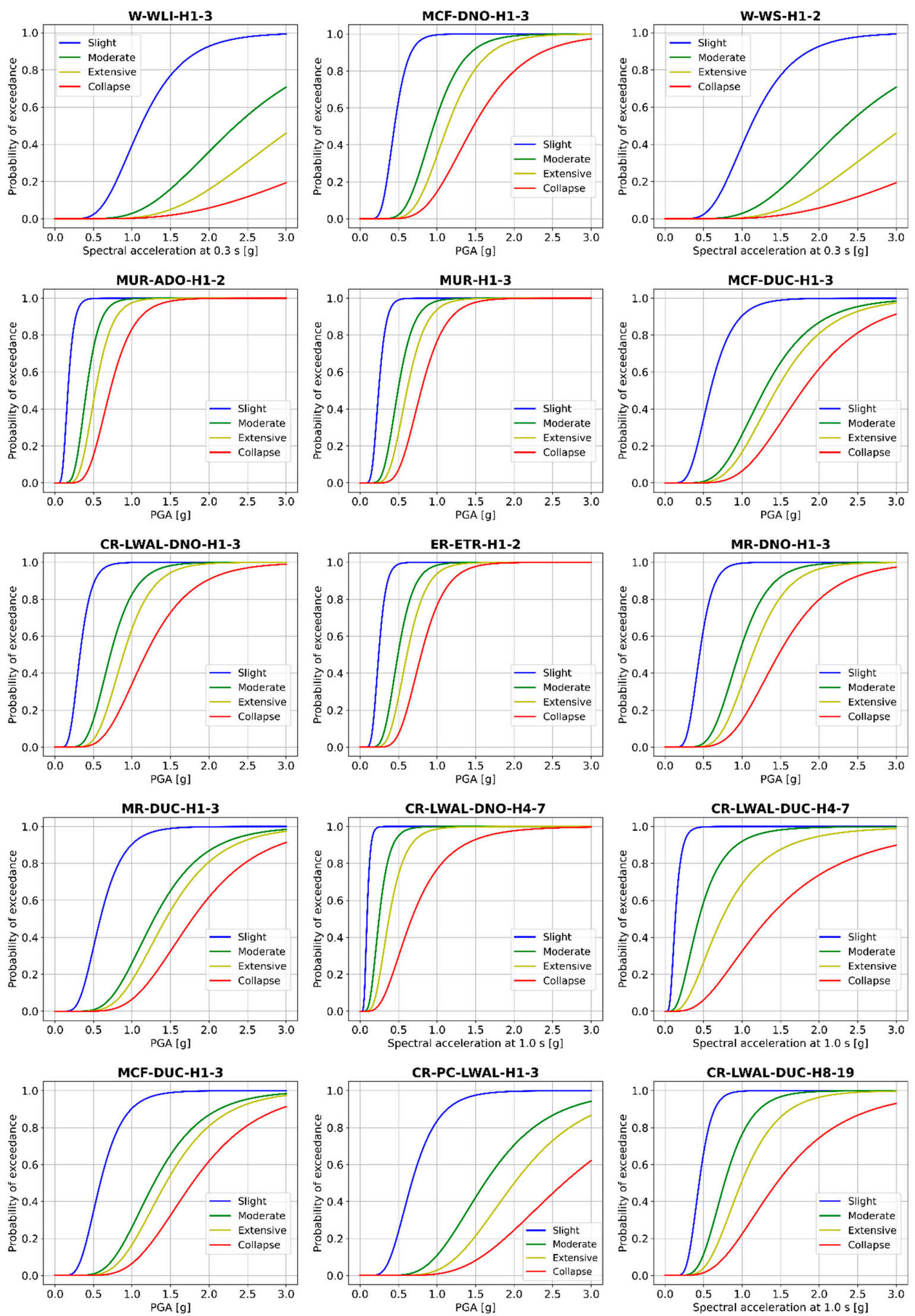

Figure 4. Fragility functions for 15 SARA building classes as reported in [69], describing their differential seismic vulnerabilities. The curves are presented in a similar order as in Figure 3. 
Table 1. SARA building classes proposed for the study area along with short descriptions. Average number of dwellings (Dwel./bdg), nighttime residents (Res./bdg), and replacement cost (Repl. Cost (USD)) are reported as in [67] and in https:/ / sara.openquake.org/ (accessed date: 21 December 2021). Average footprint area (Ft./bdg. $\mathrm{m}^{2}$ ) values are derived from the construction quality categories per dwelling as suggested in [67] as well as the mean range of storeys and dwellings per class (see Table A1). A new typology in the range A-F is proposed in terms of the similarities of their footprint areas.

\begin{tabular}{|c|c|c|c|c|c|c|}
\hline Typologies & Description & $\begin{array}{l}\text { Dwel/ } \\
\text { bdg. }\end{array}$ & $\begin{array}{c}\text { Ft/bdg. } \\
\left(\mathrm{m}^{2}\right)\end{array}$ & $\begin{array}{l}\text { Res./ } \\
\text { bdg. }\end{array}$ & $\begin{array}{l}\text { Repl. Cost } \\
\text { (USD) }\end{array}$ & $\begin{array}{l}\text { New } \\
\text { Type }\end{array}$ \\
\hline $\mathrm{ER}+\mathrm{ETR} / \mathrm{H}: 1,2$ & Rammed earth, $1-2$ stories & 1.25 & 78.79 & 4 & 43,750 & \\
\hline MUR + ADO/H:1,2 & Unreinforced masonry with adobe blocks, $1-2$ stories & 1.25 & 66.84 & 4 & 43,750 & \\
\hline MUR + STDRE/H:1,2 & Unreinforced masonry, dressed stone, $1-3$ stories & 1.25 & 65.32 & 5 & 43,750 & A \\
\hline $\mathrm{W}+\mathrm{WS} / \mathrm{H}: 1,2$ & Solid wood, between $1-2$ stories & 1.25 & 80.00 & 4 & 108,000 & \\
\hline $\mathrm{MCF} / \mathrm{DNO} / \mathrm{H}: 1,3$ & Confined masonry (non-ductile), $1-3$ stories & 4 & 46.67 & 5 & 94,500 & \\
\hline MUR/H:1,3 & Unreinforced masonry, 1-3 stories & 1.5 & 70.00 & 6 & 52,500 & $\mathrm{~B}$ \\
\hline $\mathrm{W}+\mathrm{WLI} / \mathrm{H}: 1,3$ & Light wood members, $1-3$ stories & 1.5 & 80.00 & 5 & 108,000 & \\
\hline CR/LWAL/DNO/H:1,3 & Reinforced concrete wall system (non-ductile), 1-3 stories & 4 & 160.00 & 14 & 288,000 & \\
\hline CR/LWAL/DUC/H:1,3 & Reinforced concrete wall system (ductile), 1-3 stories & 4 & 140.00 & 15 & 336,000 & C \\
\hline $\mathrm{MCF} / \mathrm{DUC} / \mathrm{H}: 1,3$ & Confined masonry (ductile), 1-3 stories & 4 & 160.00 & 5 & 288,000 & \\
\hline $\mathrm{CR}+\mathrm{PC} / \mathrm{LWAL} / \mathrm{H}: 1,3$ & Precast reinforced concrete wall system, 1-3 stories & 5 & 160.00 & 18 & 360,000 & \\
\hline $\mathrm{MR} / \mathrm{DNO} / \mathrm{H}: 1,3$ & Reinforced masonry (non-ductile), 1-3 stories & 5 & 160.00 & 18 & 360,000 & $\mathrm{D}$ \\
\hline $\mathrm{MR} / \mathrm{DUC} / \mathrm{H}: 1,3$ & Reinforced masonry (ductile), 1-3 stories & 5 & 140.00 & 18 & 360,000 & \\
\hline CR/LWAL/DNO/H:4,7 & Reinforced concrete wall system (non-ductile), 4-7 stories & 15 & 240.00 & 54 & $1,080,000$ & \\
\hline CR/LWAL/DUC/H:4,7 & Reinforced concrete wall system (ductile), 4-7 stories & 15 & 210.00 & 54 & $1,260,000$ & E \\
\hline CR/LWAL/DUC/H:8,19 & Reinforced concrete wall system (ductile), 8-19 stories & 48 & 218.15 & 173 & $4,032,000$ & $\mathrm{~F}$ \\
\hline
\end{tabular}

Table 1 also reports a new categorization (i.e., A, B, C, D, E, and F) of the SARA classes as a function of the similarities between their average footprint areas, which were conceived initially in [50]. Although this assemblage was consistent with the number of storeys for the lowest (A: 1-2 storeys) and largest values (E: 4-7; F: 8-19), the grouping for the classes ranging from 1 to 3 storeys $(B, C$, and $D)$ was made in terms of the similarities in their average footprint area values and not any other attribute (e.g., material type). This new categorization, along with the footprint, is used later in this study. A summary of the average height and footprint area $\left(\mathrm{m}^{2}\right)$ values of the reclassified typologies are reported in Table 2.

Table 2. Average footprint areas and heights derived for the six subcategories in the range A-F for Viña del Mar and Valparaíso.

\begin{tabular}{cccccc}
\hline \multirow{2}{*}{ Typology } & Average Height $(\mathbf{m})$ & \multicolumn{2}{c}{ In Viña del Mar } & \multicolumn{2}{c}{ In Valparaíso } \\
\cline { 3 - 6 } & & Average Footprint Area $\left.\mathbf{( m}^{\mathbf{2}}\right)$ & Proportion & Average Footprint Area $\left(\mathbf{m}^{\mathbf{2}}\right)$ & Proportion $^{2}$ \\
\hline A & 3.75 & 67.5 & $21 \%$ & 73 & $38 \%$ \\
B & 4.5 & 71 & $59 \%$ & 153 & $50 \%$ \\
C & 6 & 153 & $5 \%$ & 153 & $3 \%$ \\
D & 7.5 & 115 & $3 \%$ & 225 & $1 \%$ \\
E & 15 & 225 & $1 \%$ & 280 & $1 \%$ \\
F & 36 & 280 & &
\end{tabular}

It is worth noting that the building counts of the original SARA model over the administrative spatial boundaries were obtained through the dasymetric disaggregation of the population counts reported in the remote sensing products over resolutions of $\sim 1 \mathrm{~km}^{2}$. This type of procedure is comprehensively described in [72]. The disaggregation assumed a fixed number of nighttime residents per building typology. The highest spatial resolution of the aggregated exposure model of the original SARA model was made available at the third administrative division of Chile (commune). This means that our area of interest (Valparaíso and Viña del Mar) was only composed of two large geo-cells (Figure 3). Hence, one of the shortcomings of the SARA model is that the spatial distribution of buildings 
is unknown, because all of the exposure information is provided at the centroid of each geo-cell. Thus, this assumption disregards the outcomes from land use classifications, which is particularly relevant for Valparaíso, as can be seen from Figure A1. Although this resolution could be sufficient for regional seismic risk estimates [73], it would not be adequate for more detailed analysis using local ground motions or when aiming for future urban requalification (e.g., [74]). Thus, a direct downscaling of such information into a more detailed resolution was needed. This was initially carried out in [50]. This process is explained in the following section.

\subsubsection{Preliminary Model: A Simple Downscaling Using Spatial Disaggregation of Population}

This model constitutes a downscaling of the model at the commune level that spatially aggregates the building counts over a regular $500 \times 500 \mathrm{~m}$ resolution grid. It was originally reported in [50]. Achieving higher resolutions was discarded because that would require further assumptions that would increase the uncertainties of such models. Moreover, since the resulting exposure models were input for seismic risk analyses, the use of higher resolution models would lead to important and unnecessary computational problems (e.g., $[75,76])$ that we preferred to reduce at this stage. This stemmed from the need to address the aleatory uncertainties implicit in a stochastic process, such as by generating thousands of realisations of spatially correlated ground motion fields [76].

Contrary to the original SARA model that derived the number of buildings for Chile while using large-scale aggregated population counts and a nationwide mapping scheme based on the 2002 census, such metrics were rather obtained only for the specific study area. First, the urban area mapped from the land use land cover analysis (Section 3.1, Figure A1) was the external boundary of the grid. Then, the population reported in the official 2017 census data [51] was used to obtain the number of buildings of every typology based on their associated nighttime residents. This census data provides this type of information for various aggregation boundaries, ranging from small urban blocks up to large rural areas with few structures and inhabitants. Such population counts were redistributed throughout the 384 geo-cells cells that made up the $500 \times 500 \mathrm{~m}$ resolution grid. This redistribution was performed according to the ratio of enclosed urban blocks with a residential occupancy. Then, the number of buildings for each grid cell was estimated through the disaggregation of the redistributed population. This was performed by employing Equation (A1) in Appendix B as proposed in [39]. Figure 5 shows the resulting ranges of building counts obtained for this model.

Considering the relations proposed in Tables 1 and 2 for the subcategories in the range A-F and the SARA typologies, their spatial distributions were obtained as displayed in Figures 6 and 7, respectively. Note that in these three figures, the background areas (which are not subdivided into regular grids) have intermediate values for their building counts. That feature corresponds to the spatial redistribution of the UNK class throughout the entire study area (Section 3.2.1), as well as a contribution of some residential blocks of the census dataset that were not contained within the grid. 


\section{Building counts}

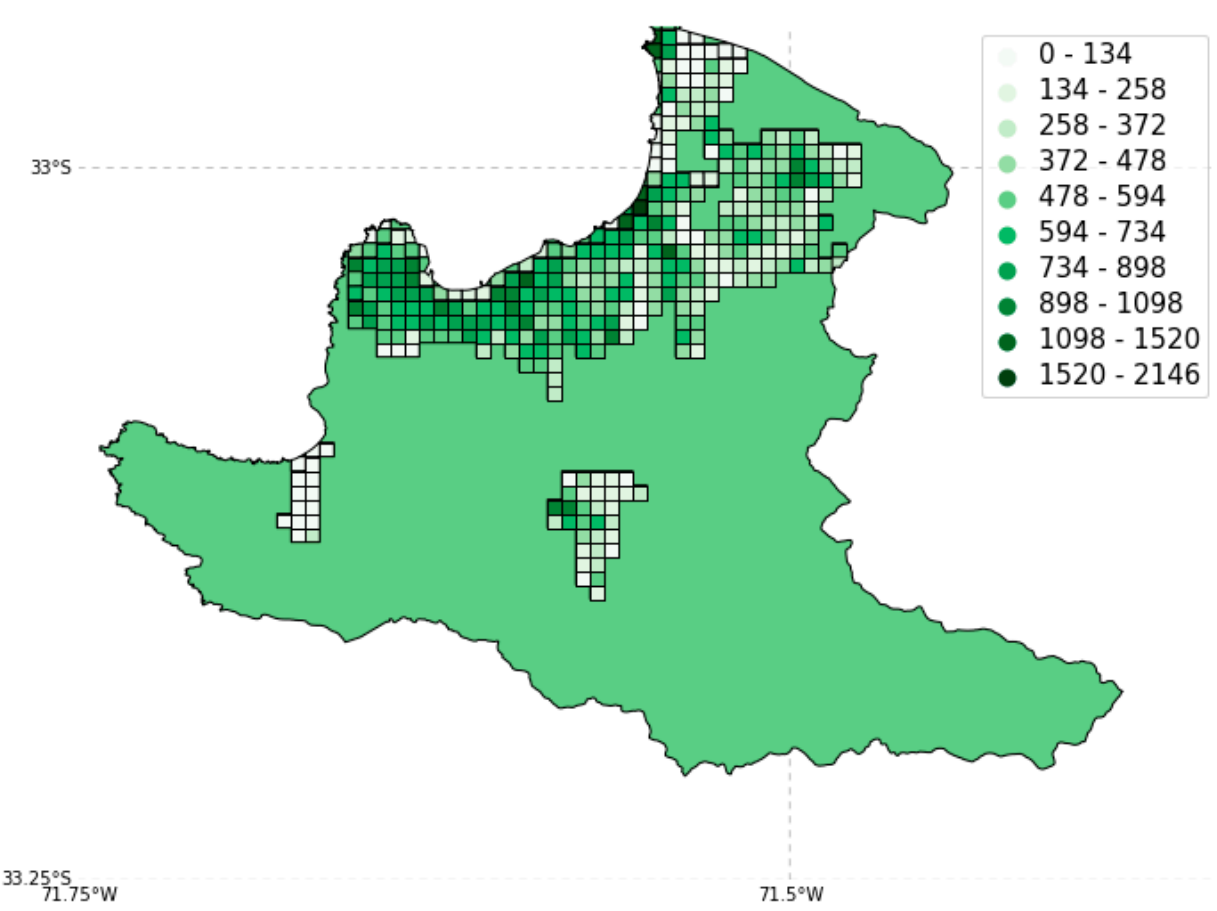

Figure 5. Inferred ranges of residential building counts in the study area. This outcome was obtained from the spatial disaggregation of nighttime residents at the block level as reported by the official 2017 Chilean census.

3.2.3. Ancillary Data Available for Valparaíso OpenStreetMap (OSM)

A large collection of building geometries for the study area has been available since the Humanitarian OpenStreetMap team task mapped the affected and surrounding areas of the 2014 Great Fire of Valparaíso to support damage assessment and the first response [77,78]. That event destroyed over 2900 homes and burned over 1000 ha. in 5 days [79]. Since then, the availability of this type of crowdsourcing data has been on the rise. Examples of the OSM building footprints for a selected area of Valparaíso are shown in Figure 8. The types of available input data for the 384 grid cells that contain residential buildings in the study area are displayed in Figure A2. 

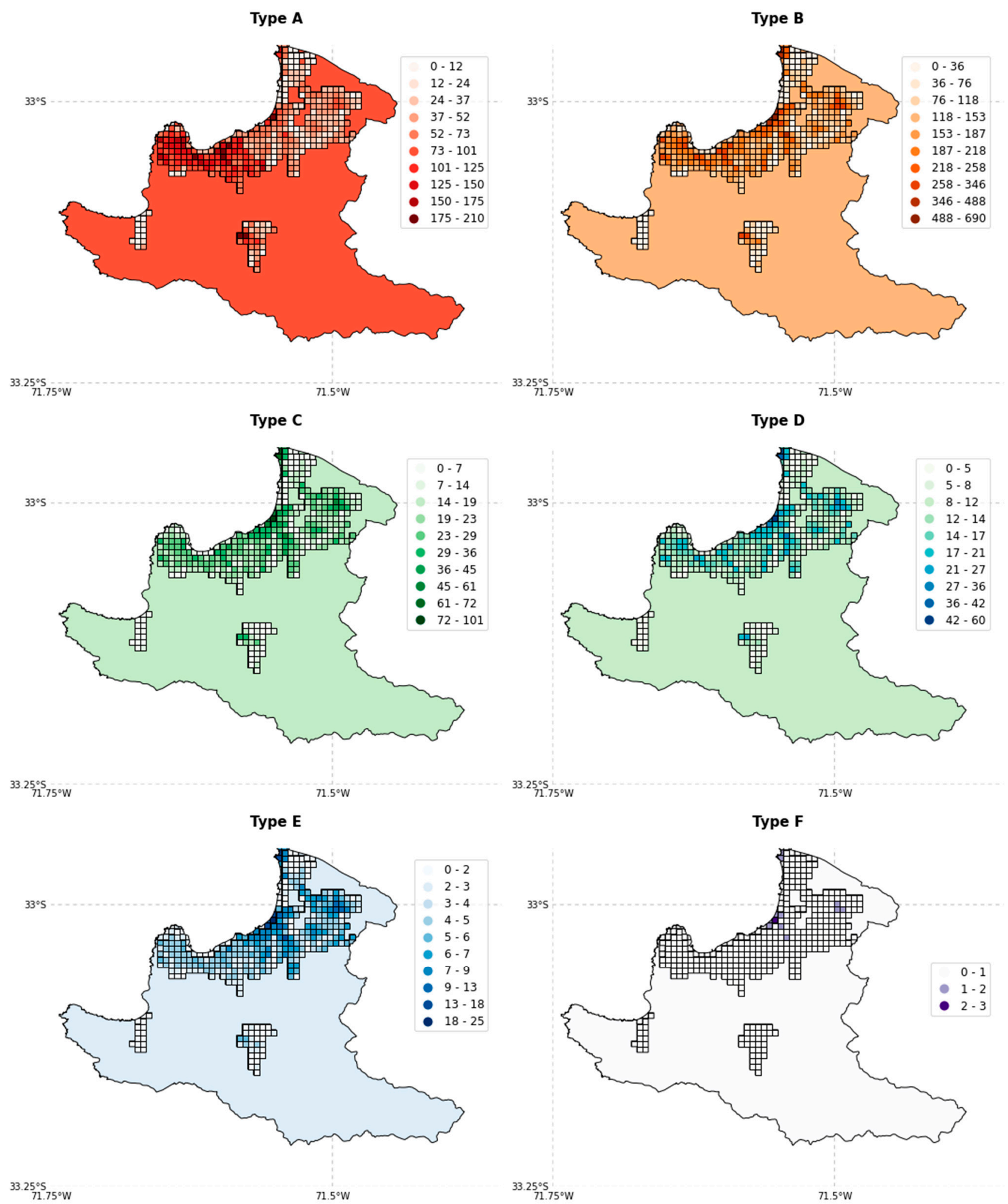

$\underset{71.75^{\circ} \mathrm{W}}{33.25^{\circ} \mathrm{g}}$

$71.5^{\circ} \mathrm{W}$

$$
33.25^{\circ} \mathrm{S} .75^{\circ} \mathrm{W}
$$

$71.5^{\circ} \mathrm{W}$

Figure 6. Spatial distributions of the building counts for the six subcategories in the range A-F obtained from the preliminary model. The latter involves a simple downscaling using the dasymetric disaggregation of the population based on the use of nighttime residents at the block level as reported by the official 2017 Chilean census. 

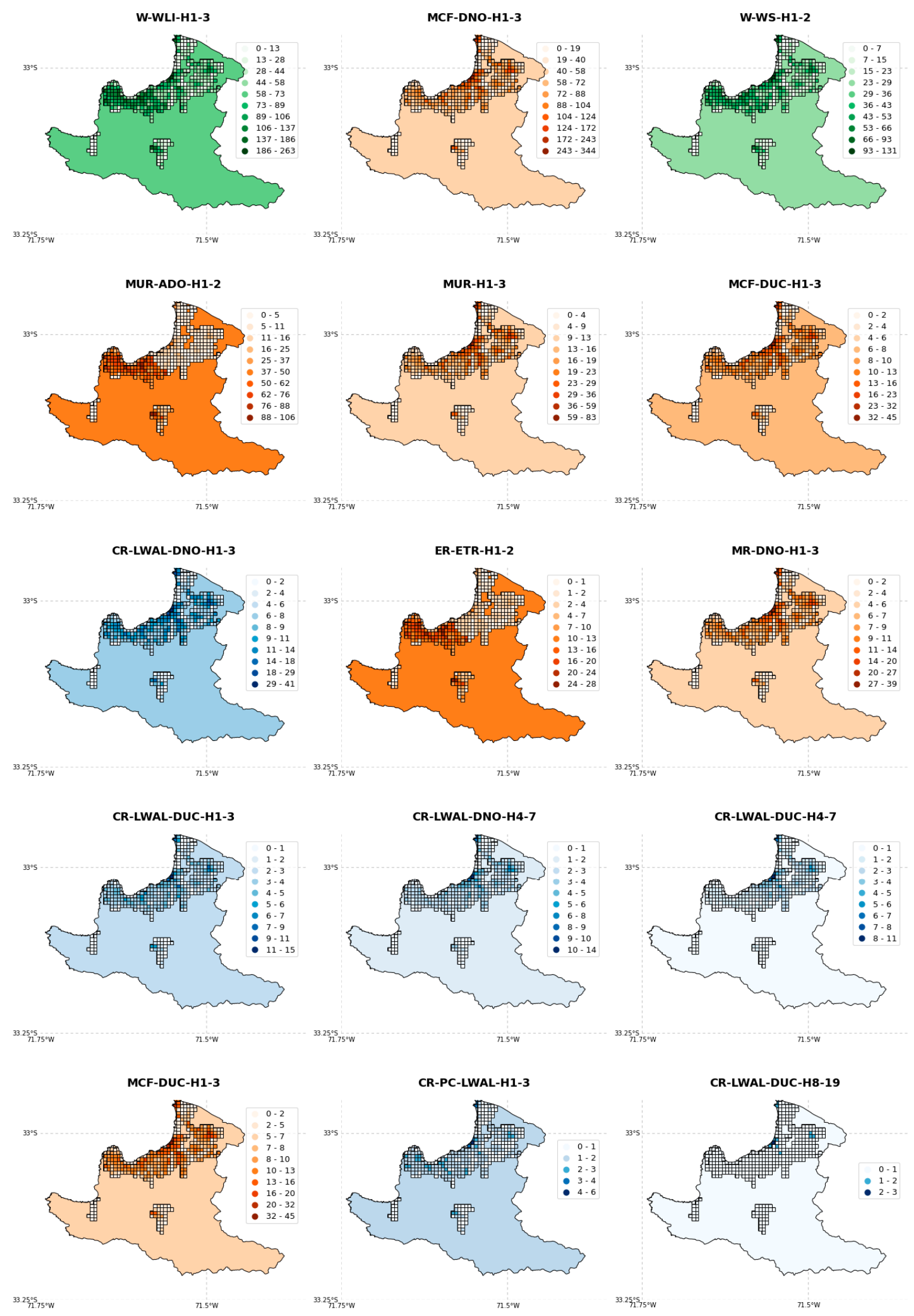

Figure 7. Spatial distributions of the building counts for the SARA typologies obtained from the preliminary downscaled model. The colour scale reflects the material type (green = wooden; orange $=$ masonry; blue $=$ reinforced concrete) . 


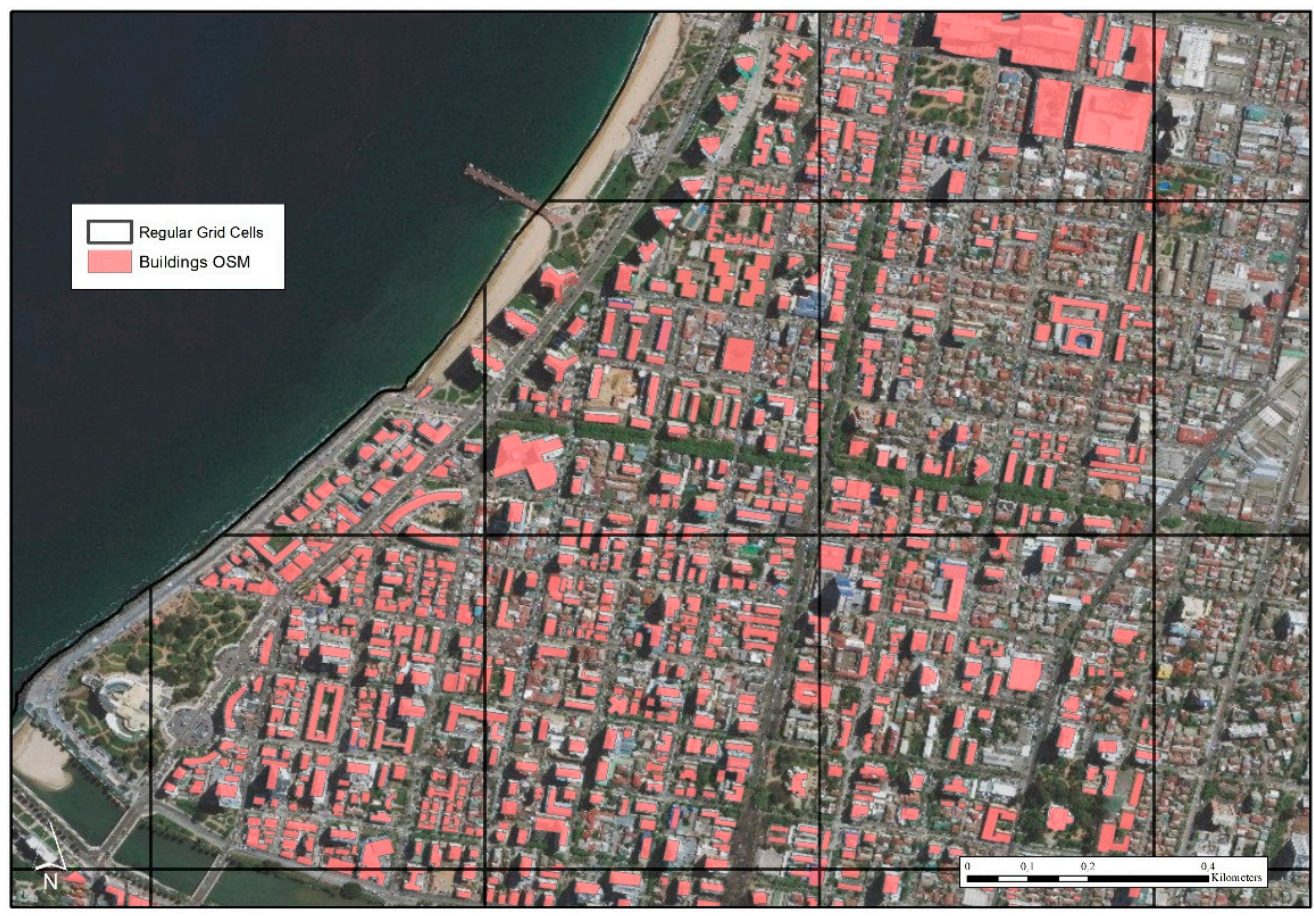

Figure 8. Building footprints for a certain area in Valparaíso (@ OpenStreetMap contributors 2021), distributed under the Open Data Commons Open Database License (ODbL) v1.0. Map data (C Google Earth 2020. Figure reprinted from [50].

\section{Data Collection of Taxonomic Attributes in Valparaíso and Building Classification}

The 604 randomly distributed buildings throughout the study area (see Appendix C, Figure A3) were inspected by expert civil engineers from the Pontificia Universidad Católica de Chile. Their attributes were collected in terms of the GEM V.2.0 taxonomy [32] while making use of the Rapid Remote Visual Screening (RRVS) web platform [80]. This tool makes use of Google Street View and OSM footprints. The resulting dataset is available in [81]. A summary of some of the observed taxonomic features as well as the method utilised in the classification of this building sample are provided in Appendix C. It is worth noting that, contrary to the approach in [59], the data collection from the RRVS surveys was not directly integrated within the Bayesian model. Instead, this information was used to compare the plausibility of the generated exposure model, as will be presented later.

\subsubsection{Bayesian Exposure Model for Valparaíso}

The theoretical conceptualisation and assumptions of this model initially proposed in [50] that relied on former approaches $[39,59]$ are presented in the Appendix D. Out of a total of 384 grid cells, 294 grid cells, for which the OSM footprint area was available (Figure A2), were updated using the Bayesian approach. The resultant probabilistic exposure model gave to each geo-cell the total number of buildings classified into the six subcategories in the range from $A$ to $F$. In order to complete the exposure information for the remaining 90 grid cells ( $23 \%$ of the model), a hybrid model was generated by combining the generated information from the Bayesian approach along with the preliminary model that comprised a simple spatial downscaling (Section 3.2.1). During this procedure, the individually surveyed buildings using the RRVS platform and their classifications (Appendix C) were used to cross-check the spatial distributions of the predominant building classes for seismic vulnerability within the grid cells. Figure 9 displays the spatial distributions of the building counts for such subcategories in the range from A to F. Once the posterior distributions for the 6 subcategories in the range A-F were obtained for each grid cell, the resulting quantities were expanded to the corresponding set of 16 SARA building classes 
using their relative proportions (Tables 1 and 2). Figure 10 does the same for the 15 selected SARA building classes.
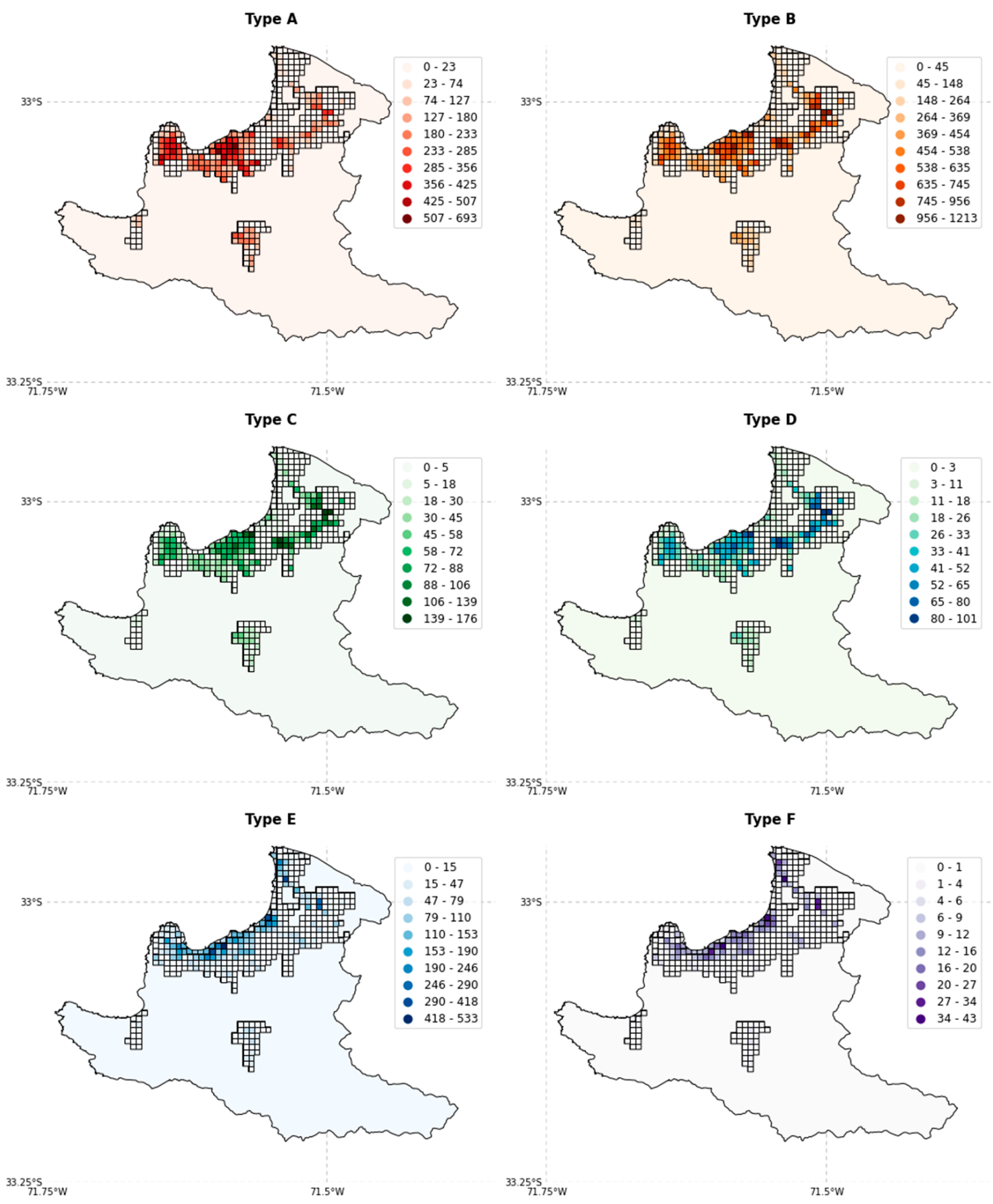

Figure 9. Spatial distributions of the building counts for the subcategories in the range A-F obtained from the probabilistic model in Valparaíso. 

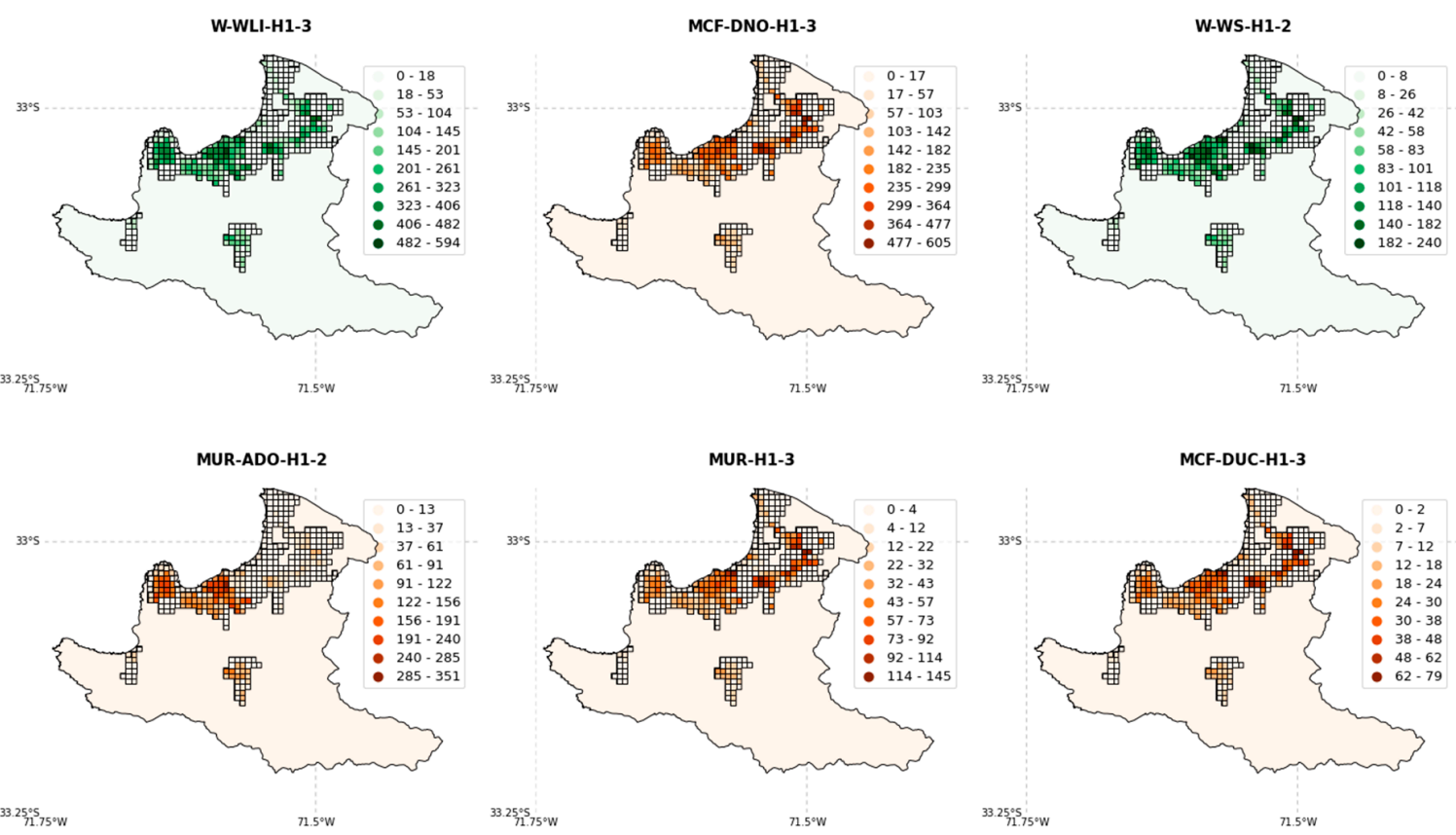

$33.25 .5755^{\circ} \mathrm{W}$

$71.5 \mathrm{w}$$$
\text { 政 }
$$
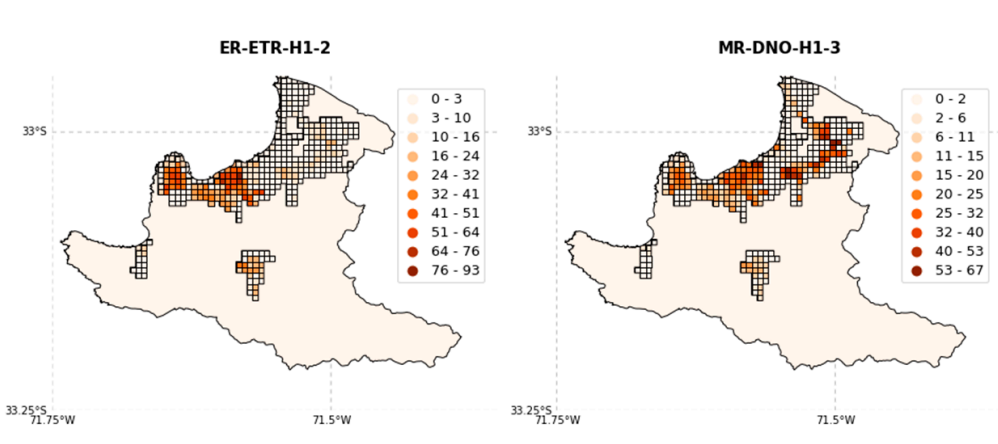

$33.25 .5 .750 \mathrm{~W}$

$7.5^{5} \mathrm{~W}$
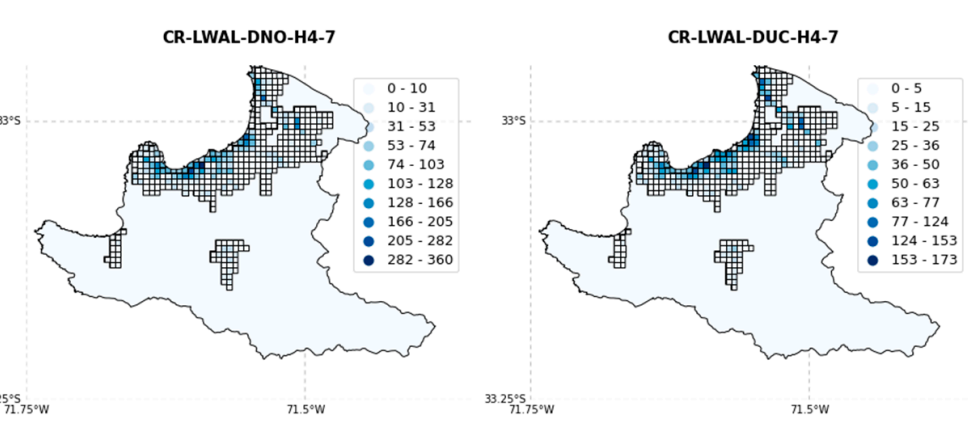

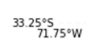
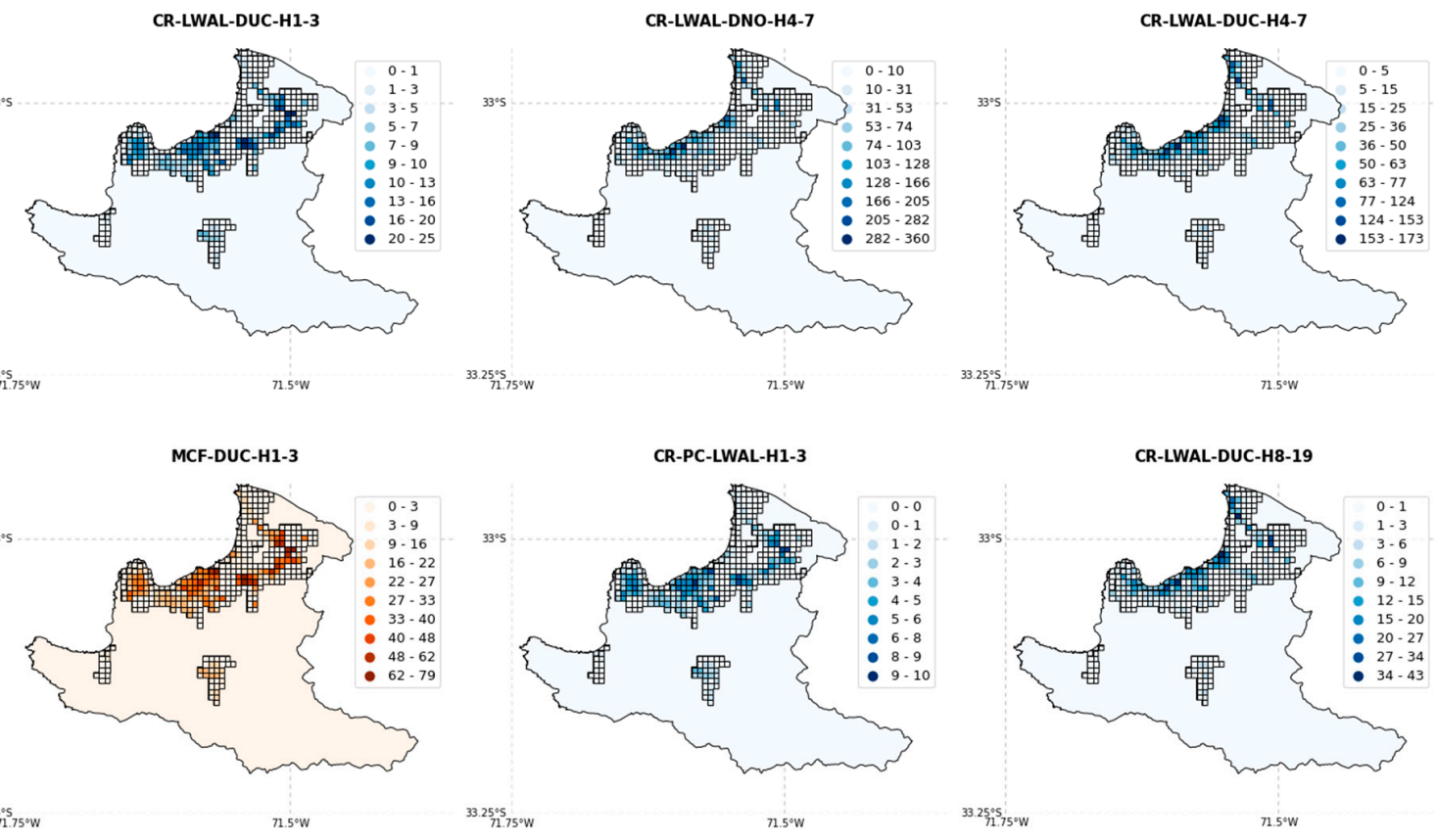

Figure 10. Spatial distributions of the building counts for the SARA typologies obtained from the probabilistic model in Valparaíso. The colour scale was selected in terms of the material type (green $=$ wooden ; orange $=$ masonry $;$ blue $=$ reinforced concrete $)$. 


\subsubsection{Comparison of Exposure Models Available for Valparaíso}

Figure 11 and Table 3 illustrate the number of buildings obtained from the three exposure models considered. Bearing in mind that the simplest model (initial communebased) was generated using the oldest data, it is not surprising that it yielded the lowest building counts. The preliminary model (simple downscaling), which was generated while inferring the building counts from the population at the block level, produced only slightly larger counts. However, the results obtained from the probabilistic approach led to important differences for the four most common types, as well as for CR-LWAL-DNOH4-7 and CR-LWAL-DUC-H4-7. Although the respective proportions per type did not significantly vary, the Bayesian approach led to an increase of $\sim 34 \%$ and $\sim 40 \%$ in the total number of buildings in comparison with the commune-based and simple downscaling models, respectively.

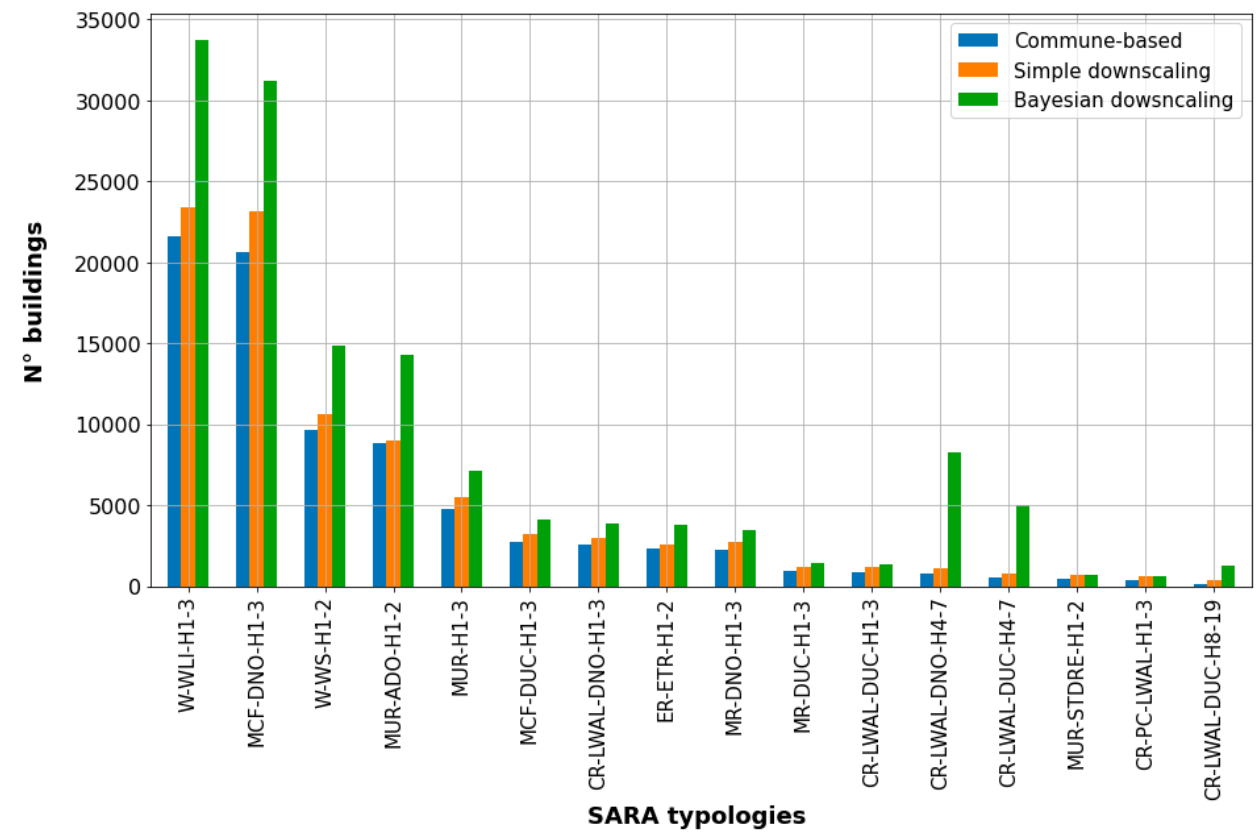

Figure 11. Comparison of the building counts per SARA typology for the three exposure models considered for Valparaíso, showing the initial commune-based model with merged classes, the preliminary model (simple downscaling), and the Bayesian model.

We remark the following concerning some of the particularities obtained for the two intermediate and more simplified exposure models for the study area:

- The first model (Section 3.2.1) is quite similar to the original SARA model, since it maintains its spatial representation over the administrative units. Its composition consists of the combination of similar classes in terms of their height.

- The second model (preliminary downscaled model, Section 3.2.2) constitutes the spatial disaggregation of the former onto higher resolutions of regular grid cells $(500 \mathrm{~m} \times 500 \mathrm{~m})$. The total number of buildings was estimated by disaggregating the population at the block level from the 2017 official Chilean census. 
Table 3. Comparison between the counts and frequencies for each building typology of the three considered exposure models.

\begin{tabular}{|c|c|c|c|c|c|c|}
\hline & $\begin{array}{c}\text { Initial Model } \\
\text { (Commune-Based with } \\
\text { Merged Classes, } \\
\text { Section 3.2.1) }\end{array}$ & Freq. (\%) & $\begin{array}{l}\text { Preliminary } \\
\text { Model (Simple } \\
\text { Downscaling, } \\
\text { Section 3.2.2) }\end{array}$ & Freq. (\%) & $\begin{array}{l}\text { Probabilistic } \\
\text { Model (Bayesian } \\
\text { Dowsncaling, } \\
\text { Section 3.2.4) }\end{array}$ & Freq. (\%) \\
\hline W-WLI-H1-3 & 21,631 & 27.29 & 23,374 & 26.22 & 33,695 & 24.97 \\
\hline MCF-DNO-H1-3 & 20,617 & 26.01 & 23,146 & 25.97 & 31,244 & 23.15 \\
\hline W-WS-H1-2 & 9610 & 12.12 & 10,619 & 11.91 & 14,835 & 10.99 \\
\hline MUR-ADO-H1-2 & 8793 & 11.09 & 9013 & 10.11 & 14,298 & 10.59 \\
\hline MUR-H1-3 & 4723 & 5.96 & 5494 & 6.16 & 7128 & 5.28 \\
\hline MCF-DUC-H1-3 & 2712 & 3.42 & 3216 & 3.61 & 4111 & 3.05 \\
\hline CR-LWAL-DNO-H1-3 & 2537 & 3.2 & 3006 & 3.37 & 3854 & 2.86 \\
\hline ER-ETR-H1-2 & 2335 & 2.95 & 2542 & 2.85 & 3801 & 2.82 \\
\hline MR-DNO-H1-3 & 2274 & 2.87 & 2728 & 3.06 & 3449 & 2.56 \\
\hline MR-DUC-H1-3 & 924 & 1.17 & 1222 & 1.37 & 1407 & 1.04 \\
\hline CR-LWAL-DUC-H1-3 & 865 & 1.09 & 1166 & 1.31 & 1311 & 0.97 \\
\hline CR-LWAL-DNO-H4-7 & 775 & 0.98 & 1065 & 1.19 & 8293 & 6.14 \\
\hline CR-LWAL-DUC-H4-7 & 502 & 0.63 & 792 & 0.89 & 4980 & 3.69 \\
\hline MUR-STDRE-H1-2 & 452 & 0.57 & 723 & 0.81 & 689 & 0.51 \\
\hline CR-PC-LWAL-H1-3 & 388 & 0.49 & 633 & 0.71 & 603 & 0.45 \\
\hline CR-LWAL-DUC-H8-19 & 129 & 0.16 & 398 & 0.45 & 1265 & 0.94 \\
\hline$\sum$ total & 79,267 & 100 & 89,137 & 100 & 134,963 & 100 \\
\hline
\end{tabular}

The former two models consider that all the geo-cells have the same proportions for the six subcategories A-F within Viña del Mar and Valparaíso (Table 2), as proposed by the original exposure model SARA. Conversely, as formerly stated, the third and definitive model (Section 3.2.4) was derived using a Bayesian approach. It estimates the building counts directly from the existing OSM footprints of residential buildings (Section 3.2.3). The exposure composition within every geo-cell was modelled as a posterior Dirichlet distribution, which was assumed to be proportional to the maximum likelihood estimation of the inferred footprint areas per building typology (Equations (A7) and (A10)). Moreover, it had the same spatial resolution adopted by the second model.

Regarding the compositions of the three aforementioned models, we observed a general trend of transversally maintaining similar proportions in their building classes (Table 3). This might mean that the construction practices for residential buildings along the study area were maintained at least from 2002 until 2020. However, certain differences can be highlighted within that general trend. Interestingly, the Bayesian-derived model led to much larger quantities for two typologies-CR-LWAL-DNO-H4-7 and CR-LWALDUC-H4-7 (Figure 11) —which are mostly located in Viña del Mar and in the vicinity of the coastline. This feature might either reflect the increasing tendency of constructing higher building rises or possible artifacts which could have been induced by incorrectly associating relatively larger building footprints to these types of moderate-rise buildings. Considering the recent practices of incrementally constructing higher-rise buildings, the first hypothesis might be plausible.

The comparison of the spatial distributions of the building classes for the second (preliminary downscaling) against the third (Bayesian-based) model, either for the A-F subcategories (Figures 6 and 9) or for the SARA classes (Figures 7 and 10), allowed us to identify some differences. As formerly described, the maps of the second model showed non-zero values for the background area. Notably, these quantities were larger for the earthen building and unreinforced masonry types (the most common types in the study area according to the original SARA model, as well as the three models presented herein). Both typologies could represent the presence of more informally constructed buildings outside the urban perimeter. A clearer spatial delimitation of these typologies is still pending and relevant, since they can be especially vulnerable to seismic actions [82]. 
Furthermore, it is interesting to see that the second model displayed quite small and unrealistic counts for the buildings characterised as walled reinforced concrete and as moderate-to-high rises (blue colours in Figure 7). This contrasted with the Bayesian model, which reported larger and well-focused areas where the presence of these typologies was expected. The presence of comparatively larger building footprints with which we associated these building types occurred in focused zones close to the coast and in Viña del Mar. These areas are typically characterised to host medium- and high-rise buildings [60], thus confirming the predictive Bayesian model. However, in the absence of robust alternatives to validate these results, the epistemic uncertainty of the estimated proportions for the walled reinforced concrete and moderate-to-high rise classes would be comparatively higher. It is worth noting that better constraining of the spatial distribution of these types of structures is still necessary because, aside from the differences in the expected counts, their associated uncertainties in the reconnaissance of their ductility levels and construction quality could significantly and differentially drive their seismic vulnerabilities [83,84].

\subsection{Generation of Seismic Ground Motion Fields for an Earthquake Scenario}

A worst-case mega-thrust earthquake scenario with a moment magnitude of Mw 9.1, similar to the one that hit Valparaíso in 1730, was considered [52]. We simulated a finite fault model and obtained their respective spatially distributed spectral accelerations using Shakyground 1.0 [85], a script that relies on the OpenQuake Engine [86]. The basic parameters used in the simulations were the following: hypocentre location (longitude $=-71.5^{\circ}$; latitude $=-32.5^{\circ}$; depth $=25 \mathrm{~km}$ ), strike $=3^{\circ}$, dip $=15^{\circ}$, and rake $=117^{\circ}$. Seismic ground motion fields were generated following sensitivity analysis, selecting various alternative parameters, namely (1) the GMPE selection, (2) the Vs30 model, and (3) the spatial correlation model.

\subsubsection{Ground Motion Prediction Equation (GMPE)}

The selection of the GMPE has been proven to be largely relevant in probabilistic seismic risk (e.g., [87,88]) as well as in scenario-based risk (e.g., [89]) for building stocks. We made use of three ground motion prediction equations (GMPEs) formerly proposed for inter-plate subduction tectonic regions to generate seismic ground motion fields for PGA, S.A(0.3 s), and S.A(1.0 s), and they were the following:

- Ghofrani and Atkinsonm, (2014) [90];

- Abrahamson et al. (2015) [91] ("BC Hydro" Model);

- Montalva et al. (2017) [92], who calibrated the former GMPE to Chile (Figure 12).

\subsubsection{Site Term (Spatial Distribution of $\mathrm{Vs}_{30}$ )}

Local site conditions, such as soft soils, can heavily impact direct loss estimates for building stocks exposed to earthquakes [93]. The "site" term of the selected GMPE considers the shear wave velocity for the 30 uppermost meters ( $\mathrm{Vs}_{30}$ values) as the only proxy. The sensitivity analysis of this term was performed considering three $\mathrm{Vs}_{30}$ conditions:

- Assuming Vsso values of $600 \mathrm{~m} / \mathrm{s}$ uniformly distributed throughout the study area. This emulated the presence of a moderately homogenous weathered rock with similar values assumed for the seabed rocks (Figure 13a).

- $\quad$ Derived from the slope proxy as proposed by the USGS [94] (Figure 13b).

- The combination between the former model and, when available, the derived values from a local seismic microzonation reported in [95] (Figure 13c).

\subsubsection{Spatial Correlation Model}

The impact of accounting for either spatial uncorrelated, correlated, or cross-correlated ground motion fields in earthquake loss models for large-scale building portfolios has been found to be highly relevant in former studies (e.g., [96]). We present as an example a single realisation of the ground motion field while considering the $\mathrm{Vs}_{30}$ values from microzonation (Figure 12c) and the Montalva et al. (2017) GMPE for three conditions: 
- Uncorrelated ground motion fields (Figure 14a);

- A spatial correlation model (Jayaram and Baker (2009)) [97] (Figure 14b-d);

- The cross-correlation model proposed by Markhvida et al. (2018) [98] (Figure 14e-g). This is useful when various intensity measures (IM), such as spectral accelerations at different periods, are used by the set of fragility functions.

In order to account for the aleatoric uncertainty of the GMPE-based ground motions, we followed the advice in [99] and computed 1000 realisations per each configuration of GMPE, $\mathrm{Vs}_{30}$, and spatial correlation. The three exposure models formerly presented were addressed as the fourth element within this sensitivity analysis to calculate their seismic vulnerability. These models, along with their fragility functions, were assembled in order to fulfil the data formats required by the Assetmaster and Modelprop software [100]. They produced inputs which, together with the ground motions provided by Shakyground, were used by the DEUS engine [101] to estimate the damage and losses. The replacement cost values suggested in [69] and loss ratios per damage state (i.e., $2 \%, 10 \%, 50 \%$, and $100 \%$ ) were used. Therefore, 81 parametric combinations for risk assessment were generated per ground motion realisation.

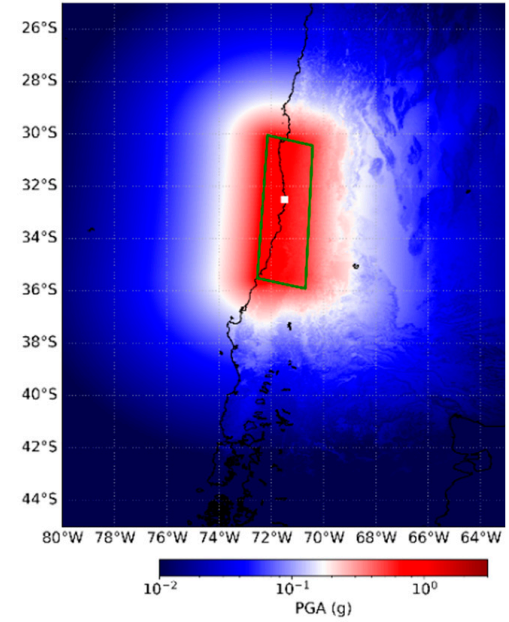

(a)

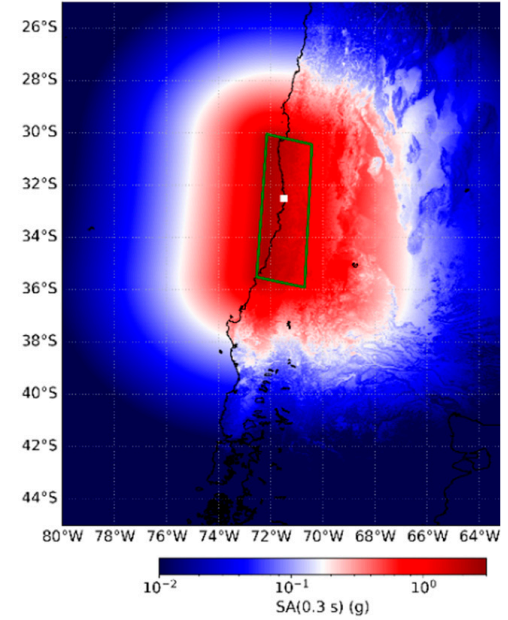

(b)

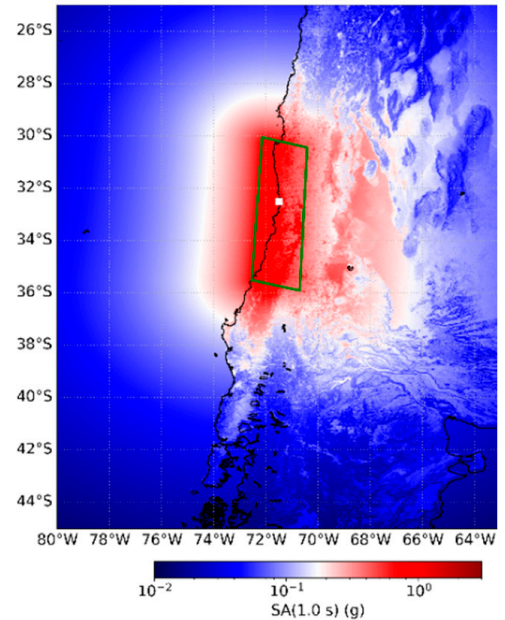

(c)

Figure 12. Median values of the Mw 9.1 earthquake for the three IMs of (a) PGA, (b) S.A (0.3 s), and (c) S.A (1.0 s) using the Montalva et al. (2017) GMPE [92] and the seismic microzonation available for the area [95].The earthquake hypocentre is shown as a white dot. The rupture plane is represented by a green rectangle.

(a) $V s_{30}=600 \mathrm{~m} / \mathrm{s}$ all through

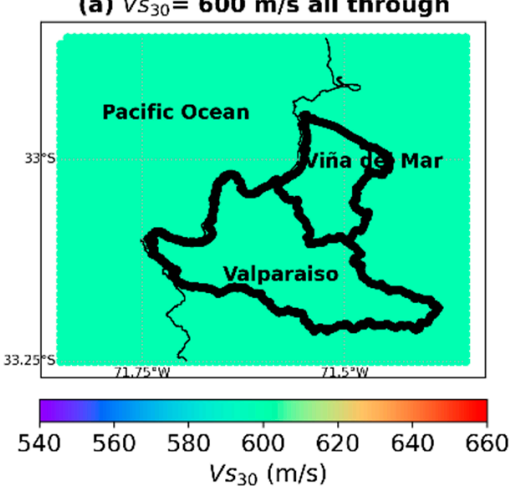

(b) $V_{S_{30}}$ from topography (USGS)

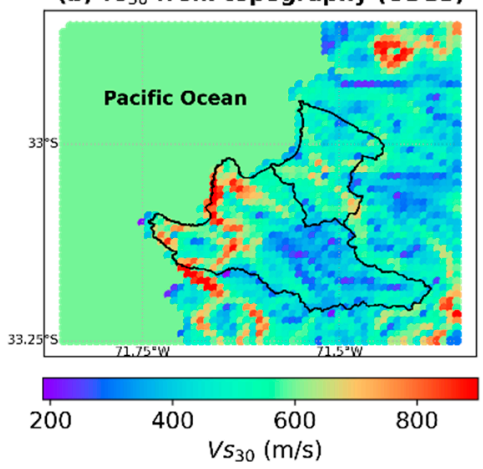

(c) $V s_{30}$ from microzonation

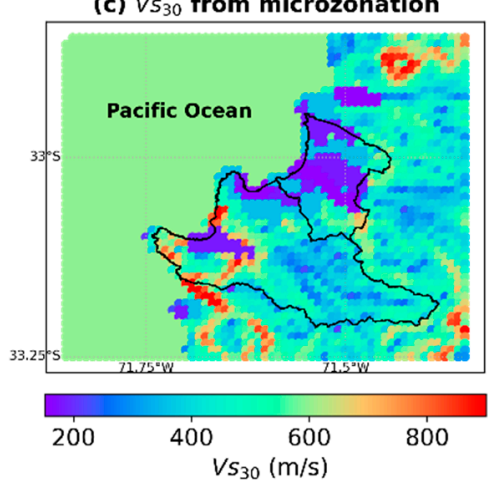

Figure 13. Distribution of the $\mathrm{Vs}_{30}$ values in Valparaíso and Viña del Mar (a) considering $600 \mathrm{~m} / \mathrm{s}$ uniformly distributed throughout, (b) as proposed by the USGS [94], and (c) the combination of the former and the values reported in the seismic microzonation [95]. 
PGA

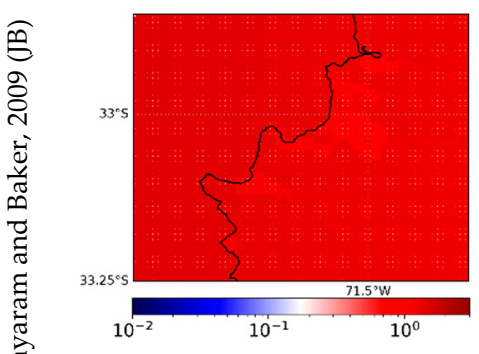

(b)

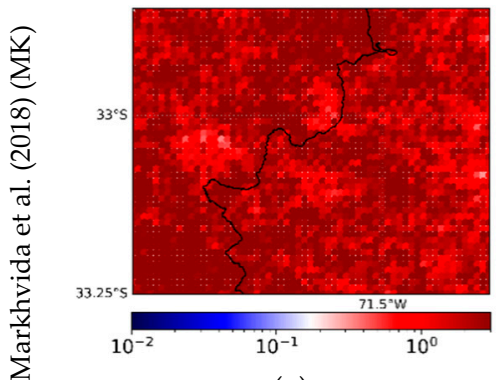

(e)
S.a(0.3 s)

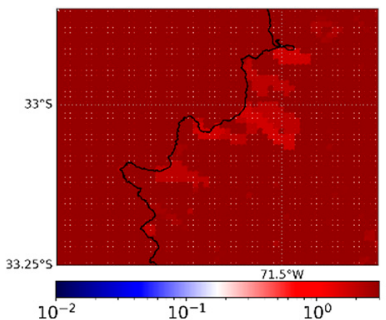

(c)

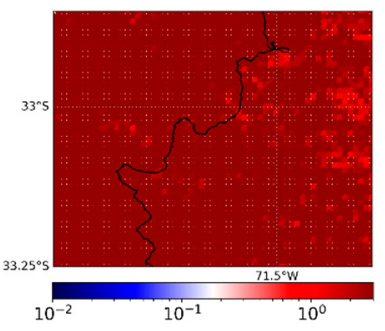

(f)
S.a(1.0 s)

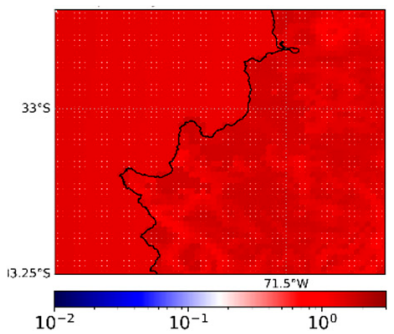

(d)

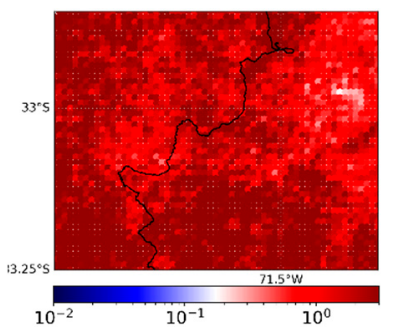

(g)

Figure 14. Single realisation of a ground motion field with the following conditions: (a) PGA uncorrelated; spatially correlated (JB) [97] for (b) PGA, (c) S.A (0.3 s), and (d) S.A (1.0 s); and cross-correlated (MK) [98] for (e) PGA, (f) S.A (0.3 s), and (g) S.A (1.0 s).

\section{Sensitivity Analyses of Scenario-Based Seismic Risk Assessment}

This systematic investigation described a condition tree that allowed us to compare the impact of individual parameters on the risk estimates and their epistemic uncertainties [102]. To avoid possible misinterpretations of the absolute economic loss values, we made the decision to provide these results in terms of normalised loss values. They were normalised with respect to the maximum loss value (among the 1000 realisations) obtained for the initial commune-based model along with the assemblage of uncorrelated ground motion fields, slope-based Vs30 values, and the Abrahamson et al. (2015) GMPE. This decision to provide normalised results is supported by the suggestions made in $[59,103]$, where it was discussed that, because of the continuously changing spatio-temporal exposure, erroneous damage forecasts can appear if the losses are shown as absolute. Moreover, normalised values allowed us to easily highlight the scale in the differences between the various models. Because of the differences in the building counts of the three exposure models, we also added a second normalisation coefficient to the nomalisation of the building counts across all the models to account for the role of the exposure composition.

Figure 15 displays the comparison between the normalised losses obtained for the three building exposure models subjected to the assembled ground motion fields shown in the vertical axis per GMPE. Figure 16 reports the same information in a collapsed and hierarchical manner for the three exposure models. Figures 15 and 16 show the comparative lower impacts that carried the selection of the GMPE upon the normalised losses across all of the evaluated cases. This might be due to the fact that they follow very similar functional forms [92]. We still can identify that, generally, the GMPE proposed by Abrahamson et al. (2015) induced the lowest estimates, whilst the Montalva et al. (2017) GMPE induced the largest variability. As reported in [96], the implementation of an inter-period crosscorrelation model imposed the largest variations regardless of the exposure model used. This condition, combined with the unrealistic case of having homogenous $\mathrm{Vs}_{30}$ values, imposed the largest values. 
(a) Initial commune-based

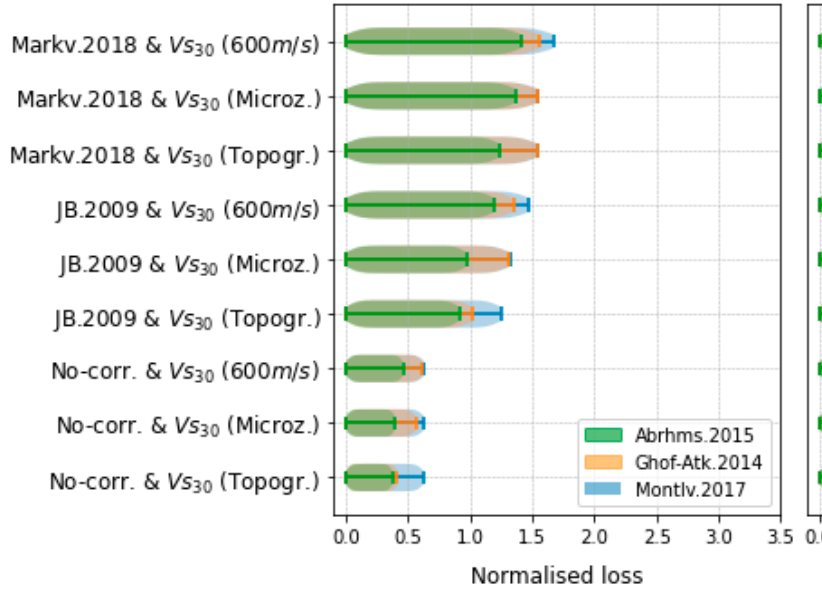

(b) Preliminary downscaled)

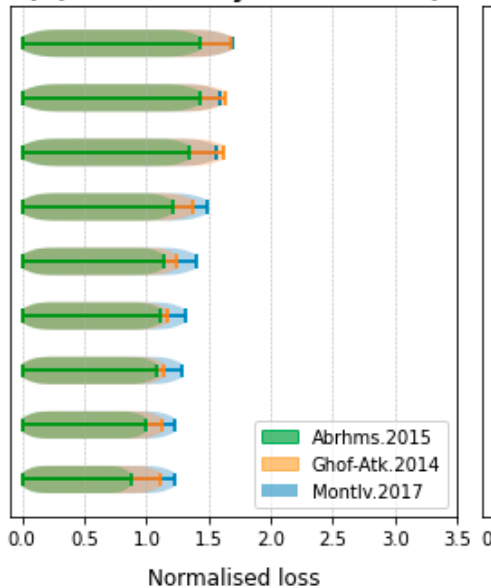

(c) Bayesian downscaled

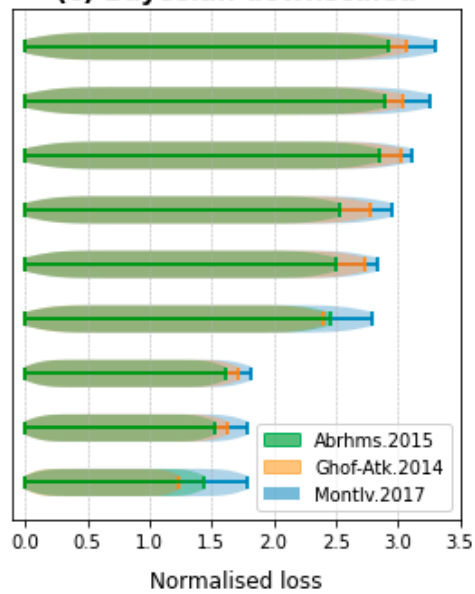

Figure 15. Normalised loss for the earthquake scenario in Valparaíso for the three exposure models (in each subplot) and 27 ground motion assemblages using the set of uncorrelated ground motions with $\mathrm{Vs}_{30}$ (Topogr.) with the Abrahams 2015 GMPE as a benchmark.

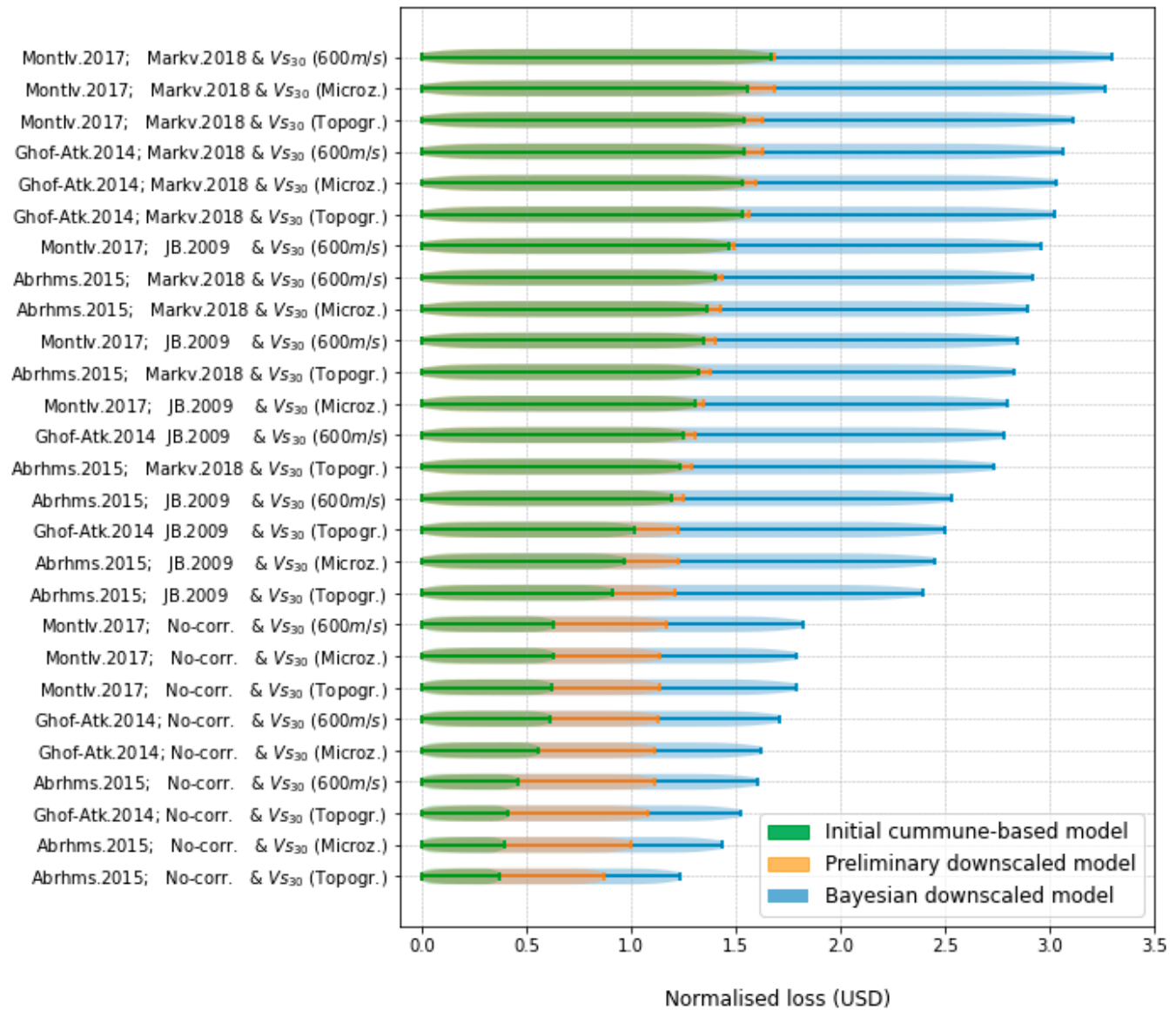

Figure 16. Similar information to that shown in Figure 15, showing the normalised loss differences between each exposure model.

We can also observe that the normalised metric was diminished when the simpler spatial correlation model and the uncorrelated ground motions were adopted. This was especially evident for the commune-based model (Figure 15a), for which the use of spatially uncorrelated ground motions led to a general underestimation of the results (values $<1.0$ with respect to the normalising model). This low-resolution model, along with having 
neglected the inter-period dependency of the fragility functions and correlated ground motions, led to unrealistic underestimations. This feature was already noted in [104]. Notably, the differences between the preliminary downscaled model and the communebased one were very low for the case of using uncorrelated GMF, regardless of the GMPE and $\mathrm{Vs}_{30}$ parametrisations. Moreover, the arrangement of the normalised risk metrics of the preliminary downscaled model (Figure 15b) presented a smoother shape in contrast with the other two exposure models. This feature was a contribution of having a more spread-out aggregation (Figure 7) made of an unrealistic portfolio composition (e.g., very few walled, high-rise, reinforced concrete buildings). Finally, the Bayesian-derived exposure model (Figure 15c) produced the highest estimated losses due to its comparative larger building counts. It might appear that the difference in these counts induced a linear increment of the losses with respect to the preliminary exposure model. However, this trend was not entirely linear. This was due to the different spatial distributions of the buildings (Figure 10) and having larger proportions of walled medium-rise RC buildings (Figure 11) which, despite being more resistant to ground shaking (Figure 4) have higher replacement costs (Table 1).

\section{Discussion}

This work was based on the assumption that the residential building stock of Valparaíso and Viña del Mar (Chile) could be entirely characterised by a set of typologies proposed by the SARA project [67]. However, exposure models could have been designed for other schemes, as proposed in [105], for the Chilean context. The SARA typologies were constrained by expert elicitation over the official 2002 Chilean census while being spatially aggregated onto two large-sized administrative units. Some classes were merged to present the initial model (Section 3.2.1). Thereafter, in order to refine the spatial representation, another preliminary exposure model was also presented employing data from 2017 (Section 3.2.2). Then, a probabilistic model that was initially presented in [50] through a Bayesian approach was recalled. Its development comprised the exploitation of recent and freely available datasets while updating its composition based on up-to-date observations.

Due to the various data sources with contrasting vintages used in deriving these three exposure models, their total building counts varied. The Bayesian model led to quantities that were $\sim 34 \%$ and $\sim 40 \%$ larger with respect to the first and second models, respectively (Table 3). Complementarily, the building counts obtained for the three models could be compared with the study of [62] which, after integrating remote sensing data products with OpenStreetMap footprints, reported a range between 64,803 and 72,412 building units for the Valparaíso commune (excluding Viña del Mar). The mean value of that range was $\sim 40 \%$ larger than the 41,722 building count reported by the first commune-based SARA model (Figure 3), whilst the values obtained by the second and third models were consistent and within the cited range.

Among the three exposure models presented, we considered that the probabilistic model provided a better representation of the updated composition of the residential building portfolio in the study area. However, this approach has several limitations and uncertainties. For instance, the posterior distribution that represents the proportions of each class was configured by making use of uninformative priors (Appendix D). Informative priors could have been obtained either if we counted with more complete OSM data about other building attributes or if we counted with expert-based prior assumptions for similar spatial units used to aggregate the model. Hence, although expert-based priors at the commune level were utilised in [59] to derive probabilistic exposure models, their resulting model was still generated at the same resolution. Therefore, it would not be wise to generalise prior distributions that were initially assumed for coarser resolutions than the one we aimed for.

It is worth testing in future studies how the increasing availability of ancillary data from OSM (which might also provide other taxonomic attributes) or from other sources (e.g., surveys and feature extraction from remote sensing) could be integrated within probabilistic exposure models. In this regard, recently reported exposure models constructed with ancil- 
lary data (e.g., $[25,47])$ are worth being continuously updated with Bayesian approaches to acknowledge their statistical nature and forecast their spatiotemporal dynamics.

Although probabilistic exposure models could have been satisfactorily obtained for higher resolutions, we considered from an early stage that such resulting models were input for seismic risk assessment. Therefore, the selected resolution for the exposure models satisfied the heterogeneities of the building stock being identifiable, while at the same time ensuring that the risk estimates from earthquake scenarios maintained a meaningful mapping resolution in concordance with the spatial variation of the intensities of the seismic ground motions [106]. Moreover, this resolution avoids unnecessary computational efforts when thousands of seismic ground motion fields (stochastically constructed) are used to assess the physical vulnerability of the exposed buildings [73,76].

The three aforementioned exposure models were utilised to perform a sensitivity analysis in scenario-based seismic risk, along with the other three components that partly parametrise the seismic ground motion fields for a single mega-thrust earthquake. They were the selection types of GMPE, Vs30 proxy, and the spatial correlation model. We observed the significant and higher importance of the exposure model compared with these evaluated parameters. This sensitivity study relied on the vague and generalised assumption of using of the Vs30 proxy to address seismic site effects [107]. Thus, addressing wave propagation studies, which were out of the scope of our work, would profit from the quality of the resultant loss estimates herein presented in the future. On a complementary note which was also out of our scope, it is worth recognising that even if we had used local correlation models for the Chilean subduction zone (such as in [108], published after this study), the use of generic and isotropic correlation models without having performed local wave form analyses in the vicinity of the study area might have induced overestimations in the risk estimates anyway [109].

It is worth noting that we are not claiming that the scenario-based economic losses for the residential building stock of Valparaíso and Viña del Mar are exhaustive. Instead, this sensitivity analysis allowed us to explore certain epistemic and aleatoric uncertainties embedded in the exposure and ground motion models. Therefore, the aforementioned observations should neither be generalised for any type of probabilistic risk assessment nor for other earthquake scenarios. Although the authors of [87] recently reported negligible differences between two alternative country-sized exposure models in sensitivity analyses for probabilistic risk, their compositions were defined through top-down approaches and not by integrating ancillary data into probabilistic models, as was presented herein. Moreover, it is worth noting that there are other components within the seismic risk chain that we did not address in this sensitivity study. For instance, it is worth exploring in future studies the role of other parameters on the final loss estimates, such as the definition of replacement costs, loss ratios per damage, and the method used for deriving more local vulnerability functions explicitly for the Chilean context (e.g., [110]) as well as the dependency on hazard intensities [111]. Consequently, more rigorous analyses, which were also beyond our scope, would comprise feature importance assessment through machine learning techniques along with macroseismic intensities calibrated through Bayesian approaches (e.g., [112]) and available datasets of damage reconnaissance after real earthquakes [113].

\section{Conclusions}

A method to spatially downscale the residential building exposure model of Valparaíso and Viña del Mar (Chile) was recalled, relying on a Bayesian formulation. As a result, a probabilistic model was generated through the integration of recent OSM data. The other two intermediate exposure models were generated by making use of out-of-date ancillary data. When we compared the three models, we observed important differences with respect to their compositions and spatial distributions. The current construction practices in the study area as well as observations from surveys confirmed that the probabilistic model provided a better representation of the composition of the residential building portfolio of interest. This type of probabilistic exposure modelling highlights the dynamic spatiotempo- 
ral evolution of the built environment. Depending on the ancillary data utilised, building exposure models may have different building counts and uncertain compositions. In order to minimise such uncertainties, high-quality data should be continuously integrated into probabilistic models.

This study has provided a partial understanding of the importance of counting with incrementally updated exposure models (i.e., when their composition is probabilistically constructed) and their crucial role in earthquake loss models. Through a sensitivity analysis in scenario-based seismic risk, we indicated the importance of constantly constraining the seismic ground motions along with a good level of knowledge of the building stock. Although we did not provide absolute numbers of direct economic losses, the presented results can be used to improve the knowledge of individual parts of the seismic risk chain through future studies.

Author Contributions: Conceptualization, Massimiliano Pittore, Juan Camilo Gómez Zapata. and Raquel Zafrir; methodology, Massimiliano Pittore; investigation, Raquel Zafrir, Juan Camilo Gómez Zapata. and Yvonne Merino; writing — original draft preparation, Juan Camilo Gómez Zapata and Raquel Zafrir; writing—review and editing, Juan Camilo Gómez Zapata; supervision, Massimiliano Pittore. This study presents the initial results shown at the EGU-2020 conference [28] and the study elaborated by Raquel Zafrir [50]. The latter was submitted to the Stuttgart Technology University of Applied Sciences as a requirement for the master's degree in photogrammetry and geoinformatics in 2020. All authors have read and agreed to the published version of the manuscript.

Funding: This research was funded by the RIESGOS and RIESGOS 2.0 projects, funded by the German Federal Ministry of Education and Research (BMBF) with Grant No. 03G0876A-J and 03G0905A-H, respectively. These projects are part of the funding programme CLIENT II-International Partnerships for Sustainable Innovations'. Yvonne Merino was funded by the Research Center for Integrated Disaster Risk Management (CIGIDEN), ANID/FONDAP/15110017.

Institutional Review Board Statement: Not applicable.

Informed Consent Statement: Not applicable.

Data Availability Statement: The data regarding the building surveys have been made available in $[81,114]$. The software utilised in this study are freely available from $[85,100,101]$. The data and codes related to the Bayesian exposure models presented in this study are available on request from the corresponding author.

Acknowledgments: We would like to also thank Paula Aguirre, Tamara Cabrera, Rosita Jünemann (PUC, CIGIDEN), Javiera Yáñez Sánchez, and Mercedes Eva Parada (MVUC) for having discussed with us exposure modelling, physical vulnerability, and risk in Valparaíso and Viña del Mar. We thank Catalina Yepes (GEM) for having provided the SARA model. Our gratitude also goes to Fabrice Cotton, Jörn Lauterjung (GFZ), Patrick Aravena, and Christian Geiß (DLR) for their support during the elaboration of this study. We thank Kevin Fleming for the careful proofreading. We thank the editors and three anonymous reviewers who provided constructive feedback.

Conflicts of Interest: The authors declare no conflict of interest. 


\section{Appendix A. Spatial Delimitation of the Urban Area and Available Data Sources for Building Exposure Modelling}

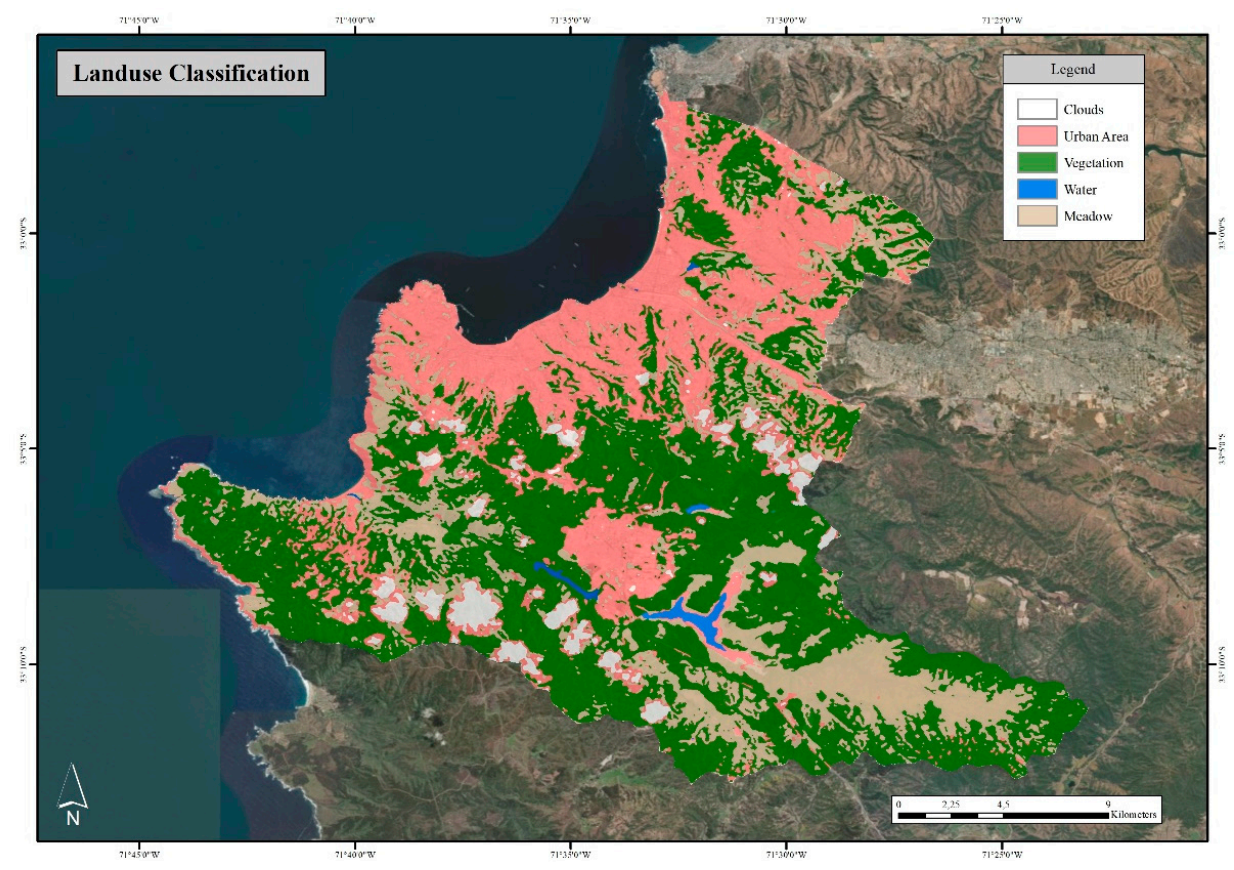

Figure A1. Land use classification for the study area. Map data @ Google Earth 2020. Figure modified from [50].

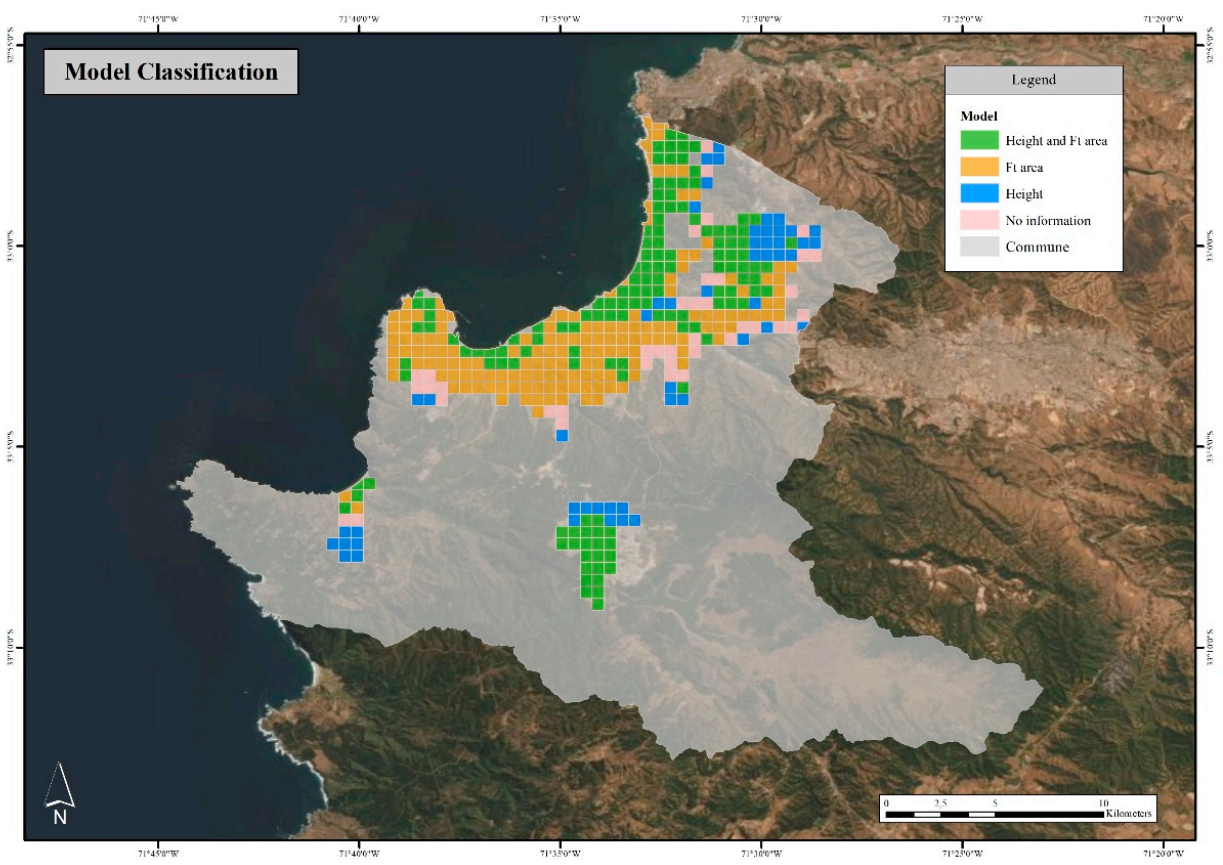

Figure A2. Categories according to the available input data in the study area, with 136 grid cells represented by green colour having information on build-up height according to [50] as well as the OSM footprint area (Section 3.2.3), 51 grid cells represented with blue colour having information about the build-up height and density from remote sensing data products (as studied by [50]), 158 grid cells represented by orange colour having a complete information only about the footprint area from OSM, and 39 grid cells represented by pink colour having no input information. Map data @ Google Earth 2020. Figure modified from [50]. 
Appendix B. Assumptions Followed in the Prelimary Model to Obtain Building Counts from Population and Footprint Areas per Typology

Pittore et al. (2020) [39] proposed using Equation (A2) to obtain the number of buildings belonging to every class within each geo-cell:

$$
\mathrm{N}_{\mathrm{b}}=\frac{\text { pop }_{\mathrm{gc}}}{\sum_{\mathrm{i}=1}^{\mathrm{k}} \theta_{\mathrm{i}} * \text { pop }_{\mathrm{b}_{\mathrm{i}}}}
$$

where pop $\mathrm{gc}_{\mathrm{c}}$ and $\mathrm{N}_{\mathrm{b}}$ are the total population and the total number of buildings in the geo-cell, respectively, $\mathrm{N}_{\mathrm{bi}}, \theta_{\mathrm{i}}$, and pop ${ }_{\mathrm{bi}}$ are the number of buildings per typology $b_{\mathrm{i}}$, their proportion per building, and the night-time residents, respectively, and $\mathrm{N}_{\mathrm{bi}}$ already comprises a dwelling-to-building ratio. 
Table A1. Procedure followed in deriving the building footprint area values for each SARA typology in Valparaíso according to the descriptions in Section 3.2.1.

\begin{tabular}{|c|c|c|c|c|c|c|c|c|c|c|c|}
\hline Taxonomy & Dwellings & Buildings & $\begin{array}{c}\text { Mean } \\
\text { Number of } \\
\text { Storeys }\end{array}$ & $\begin{array}{c}\text { Reference } \\
\text { Average Area per } \\
\text { Dwelling }\left(\mathrm{m}^{2}\right)\end{array}$ & Population & $\begin{array}{l}\text { Construction } \\
\text { Quality }\end{array}$ & $\begin{array}{c}\text { Area m² } \\
\text { Dwellings }\end{array}$ & $\begin{array}{l}\text { Floor Area } \\
\text { (m) }\end{array}$ & $\begin{array}{l}\text { Floor Area } \\
\left(\mathrm{m}^{2}\right) \text { per } \\
\text { Building }\end{array}$ & $\begin{array}{c}\text { Average } \\
\text { Floor Area } \\
\text { per Building }\end{array}$ & $\begin{array}{l}\text { Sub- } \\
\text { Categories }\end{array}$ \\
\hline $\mathrm{W}+\mathrm{WS} / \mathrm{H}: 1,2$ & 1464.4 & 1464.4 & 1 & 80 & 5420 & Low & 117,152 & $117,152.1$ & 80.00 & \multirow{4}{*}{73.24} & \multirow{4}{*}{$\mathrm{A}$} \\
\hline $\mathrm{ER}+\mathrm{ETR} / \mathrm{H}: 1,2$ & 2348.8 & 5909.5 & 1.25 & 70 & 30,771 & Low & 582,001 & $465,600.8$ & 78.79 & & \\
\hline MUR + ADO/H:1,2 & 9185.9 & 7472.5 & 1.25 & 70 & 33,997 & Low & 643,013 & $514,410.4$ & 68.84 & & \\
\hline $\begin{array}{c}\text { MUR + } \\
\text { STDRE/H:1,2 }\end{array}$ & 5747.8 & 4928 & 1.25 & 70 & 21,273 & Low & 402,346 & $321,876.8$ & 65.32 & & \\
\hline $\mathrm{MCF} / \mathrm{DNO} / \mathrm{H}: 1,3$ & 6841.9 & 876.4 & 1.5 & 70 & 3244 & Low & 61,348 & $40,898.7$ & 46.67 & \multirow{2}{*}{65.56} & \multirow{2}{*}{$\mathrm{B}$} \\
\hline $\mathrm{W}+\mathrm{WLI} / \mathrm{H}: 1,3$ & $16,254.2$ & $10,836.1$ & 1.5 & 80 & 60,157 & Low & $1,300,336$ & $866,890.7$ & 80.00 & & \\
\hline CR/LWAL/DNO/H:1,3 & 34384.3 & 1096.1 & 2 & 80 & 16,226 & Low & 350,744 & 175,372 & 160.00 & \multirow{3}{*}{153.33} & \multirow{3}{*}{$\mathrm{C}$} \\
\hline CR/LWAL/DUC/H:1,3 & $3 \quad 1461.1$ & 365.3 & 2 & 70 & 5408 & Low & 102,277 & $51,138.5$ & 140.00 & & \\
\hline MCF/DUC/H:1,3 & 4501.3 & 1125.3 & 2 & 80 & 16,659 & Low & 360,104 & 180,052 & 160.00 & & \\
\hline \multirow{3}{*}{$\begin{array}{c}\mathrm{CR}+ \\
\mathrm{PC} / \mathrm{LWAL} / \mathrm{H}: 1,3 \\
\mathrm{MR} / \mathrm{DNO} / \mathrm{H}: 1,3 \\
\text { MR/DUC/H:1,3 }\end{array}$} & 1016.9 & 203.4 & 2.5 & 80 & 3764 & Low & 81,352 & $32,540.8$ & 160.00 & \multirow{3}{*}{153.33} & \multirow{3}{*}{$\mathrm{D}$} \\
\hline & 4652.5 & 930.5 & 2.5 & 80 & 17,219 & Low & 372,200 & 148,880 & 160.00 & & \\
\hline & 2077.7 & 415.5 & 2.5 & 70 & 7690 & Low & 145,439 & $58,175.6$ & 140.00 & & \\
\hline \multicolumn{2}{|c|}{$\begin{array}{l}\text { CR/LWAL/DNO/H:4,7 } \\
4316 \\
\text { CR/LWAL/DUC/H:4,7 } 2076.6\end{array}$} & 138.4 & 5 & 70 & 76,856 & Medium & 145,362 & $29,072.4$ & 210.00 & 225.04 & E \\
\hline \multicolumn{2}{|c|}{ CR/LWAL/DUC/H:8,19 1656.9} & 34.5 & 12 & 70 & 6132 & High & 115,983 & 9665.3 & 280.15 & 280.15 & $\mathrm{~F}$ \\
\hline
\end{tabular}




\section{Appendix C. Data Collection of Building Attributes in Valparaíso and}

\section{Their Classification}

Out of the entire sample made up of 604 buildings [81] (Figure A3), we present in Table A2 some of the observed attributes values found during the survey for the building depicted in Figure A4. The distributions of the observed values of four attribute types are shown in Figure A5. Short descriptions of these attributes are shown in Table A3.

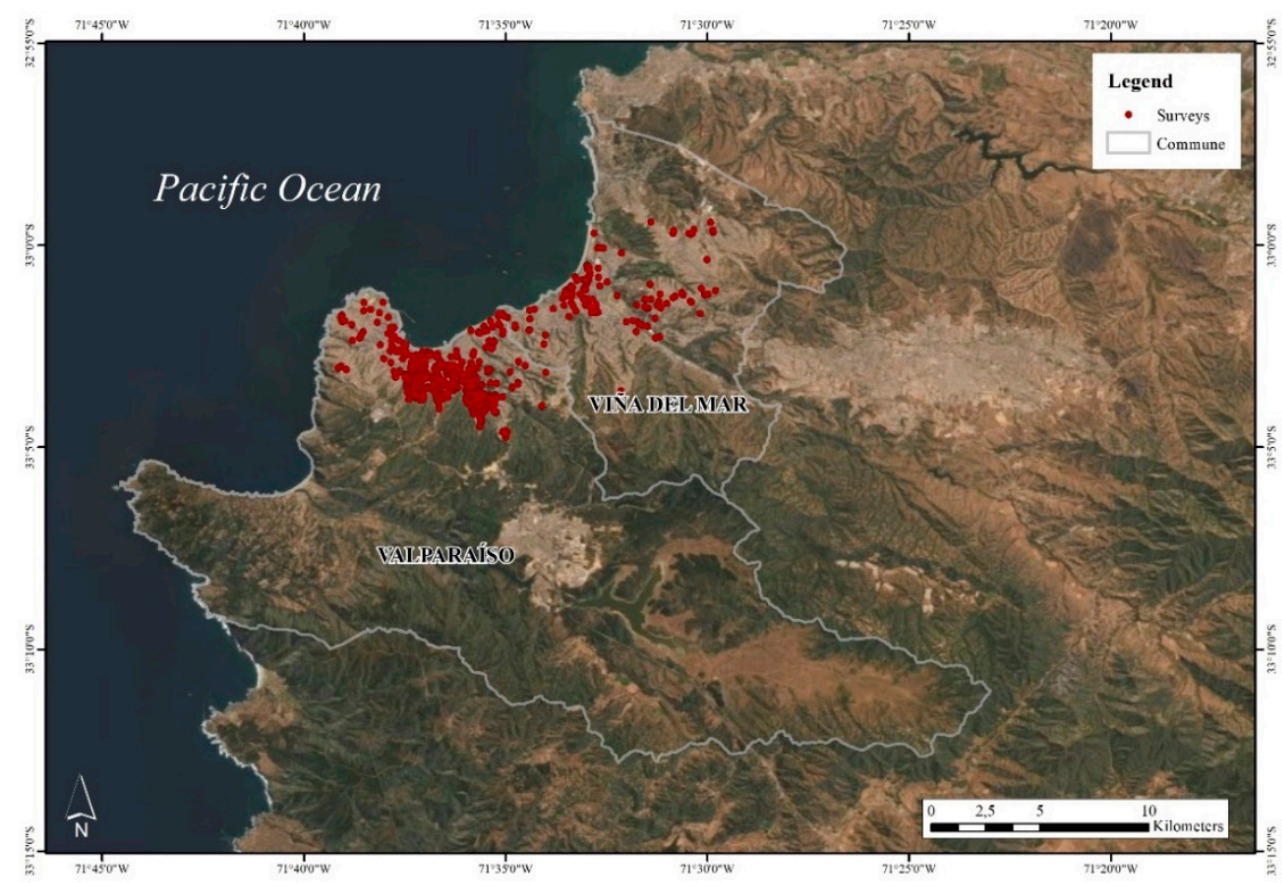

Figure A3. Location of the RRVS building survey in Valparaíso. Map data: figure modified from [59]. Map data (C) Google Earth 2020

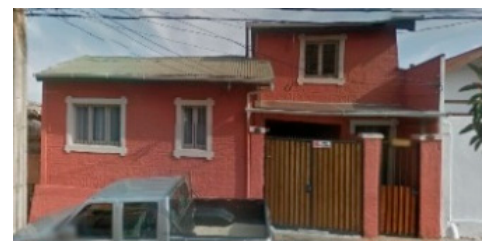

Figure A4. Façade of inspected building (ID = 599 in [81]). Image data () Google Street View 2019.

Table A2. Data collection for the building in Figure A4.

\begin{tabular}{cc}
\hline Attribute Type & Attribute Value \\
\hline Material type & MCF \\
Material technology & CL99 \\
Material property & MO99 \\
Lateral load-resisting system (LLRS) & LWAL \\
Non-structural exterior walls & EWMA \\
Roof shape & RSH2 \\
Roof coverage material & RMT6 \\
Roof system material & RWO \\
Roof system type & RWO1 \\
Floor material & FC \\
Floor type & FC99 \\
Floor connections & FWCP \\
Number of storeys & 2 \\
Ductility of the LRRS & DU99 \\
\hline
\end{tabular}




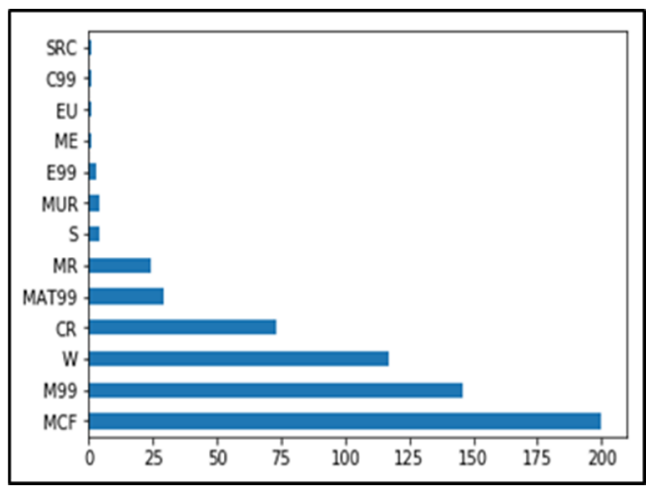

(a)

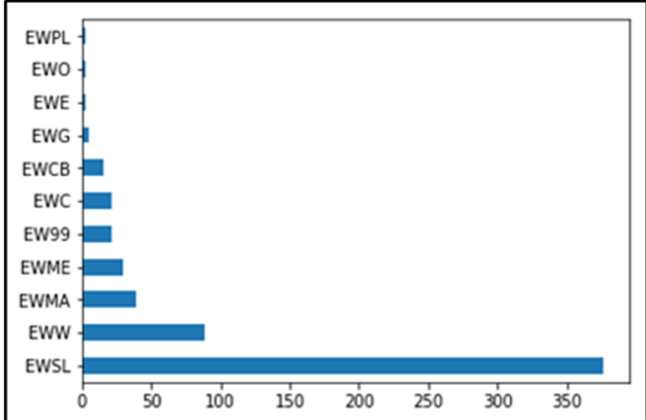

(c)

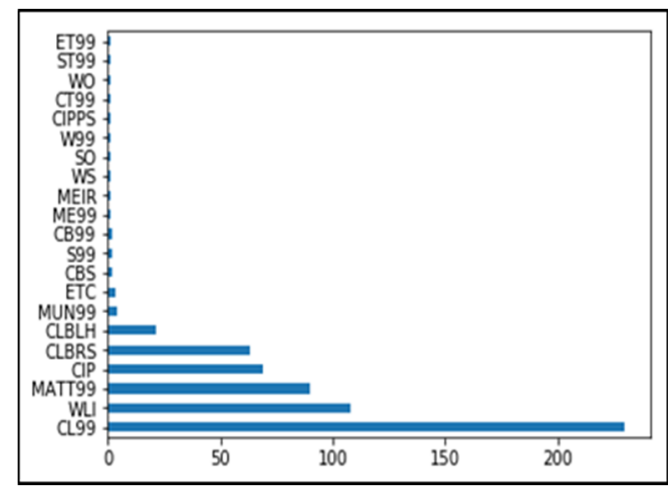

(b)

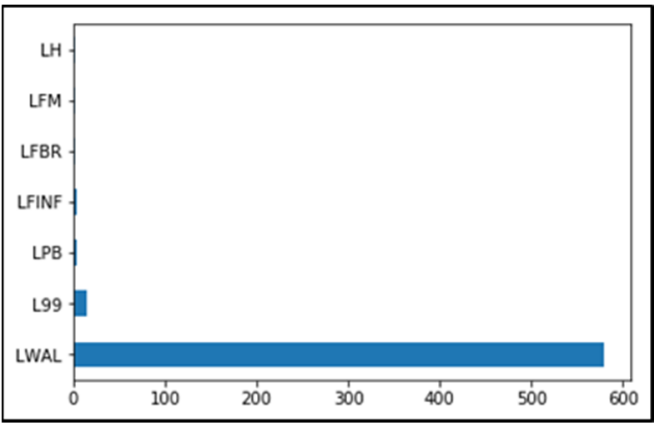

(d)

Figure A5. Distribution of attribute values within the GEM V.2.0 taxonomy for 604 inspected buildings in Valparaíso for (a) material type, (b) material technology, (c) non-structural exterior walls, and (d) lateral load-resisting system.

To classify the surveyed building sample, we followed the method proposed in [33]. $\mathrm{v}_{\mathrm{ik}}$ is an attribute value belonging to the taxonomic description $\{\mathrm{F}(\mathrm{b})\}_{\mathrm{m}}$ of the considered building $b$, and $s_{i k}^{c}$ is the fuzzy score measuring the level of compatibility of the attribute values $v_{i k}$ with respect to a given class $T_{k}^{A}$ in the reference Schema $A$ for every category value $\left\{v_{i k}, k=1, \ldots, m_{i}\right\}$ that the attribute type $a_{i}$ can take. A set of triangular fuzzy numbers (TFNs) that comprise seven increasing levels of compatibility from "- - -", "- -", "-", " +", "+ +", and " +++ " were assigned through expert elicitation. Every $\mathrm{a}_{\mathrm{i}}$ within Schema A had an associated weight $\mathrm{w}_{\mathrm{i}}$ (i.e., a crisp (non-fuzzy) number) which ranked and integrated the different attribute types within the local schema:

$$
\sum_{i=1}^{n} w_{i} \sum_{i=1}^{m_{i}} \delta_{i k}(b) s_{i k}^{T_{k}^{A}} \text { with } \delta_{i k}(b)=\left\{\begin{array}{c}
1 \text { if } v_{i k} \in \mathrm{T}_{k}^{A} \\
0 \text { otherwise }
\end{array}\right.
$$

The assignment of the most likely class was carried out in a post-processing stage and within a fully probabilistic framework by evaluating the level of compatibility between the observed building attributes and the classes available within the considered schema. Making use of the former method, we classified the surveyed buildings while reusing the dataset provided in [114], which comprised the disaggregation of the SARA scheme into the attributes comprised in the GEM v.2.0 taxonomy along with their associated fuzzy compatibility scores with a single weighting scheme. After the evaluation of their degree of belonging, we obtained the differential compatibility levels for each building. Figure A6 shows the differential compatibilities of the building displayed in Figure A4 to be categorised as one of the 16 SARA typologies. Since its ductility was not identified (Table A3), the highest scores were obtained for two types: MCF-DNO-H1-3 and MCF-DUCH1-3. Under such a circumstance, the non-ductile option was chosen. After performing this classification for the entire sample, we obtained the distribution of typologies for the 
building sample shown in Figure A7. Notably, 11 building classes out of the 16 proposed were observed.

Table A3. Observed attribute values incorporated into the four attribute types in Figure A5.

(a) Material Type

SRC: Concrete, composite with steel section

C99: Concrete, unknown reinforcement

EU: Earth, unreinforced

ME: Metal (except steel)

E99: Earth, unknown reinforcement

MUR: Masonry, unreinforced [MUR]

S: Steel

MR: Masonry, reinforced

MAT99: Unknown material

CR: Concrete, reinforced

W: Wood

M99: Masonry, unknown reinforcement

MCF: Masonry, confined (MCF) (b) Material Technology

ET99: Unknown earth technology

ST99: Stone, unknown technology

WO: Wood, other

WS: Solid wood

MEIR: Iron

ME99: Metal, unknown

CB99: Concrete blocks, unknown type

S99: Steel, unknown

CBS: Concrete blocks, solid

ETC: Cob or wet construction

MUN99: Masonry unit, unknown

CLBLH: Fired clay hollow blocks or tiles

CLBRS: Fired clay solid bricks

CIP: Cast-in-place concrete

MATT99: Unknown material

WLI: Light wood members

CL99: Fired clay unit, unknown type

(c) Non- Structural Exterior Walls

EWPL: Plastic or vinyl exterior walls, various

EWO: Material of exterior walls, other

EWE: Earthen exterior walls

EWG: Glass exterior walls

EWCB: Cement-based boards for exterior walls

EWC: Concrete exterior walls

EW99: Unknown material of exterior walls

EWME: Metal exterior walls

EWMA: Masonry exterior walls

EWW: Wooden exterior walls

d) Lateral Load Resisting System

LH: Hybrid lateral load-resisting system

LFM: Moment frame

LFBR: Braced frame

LFINF: Infilled frame

LPB: Post and beam

L99: Unknown lateral load-resisting system

LWAL: Wall

EWSL: Stucco finish on light framing for exterior walls

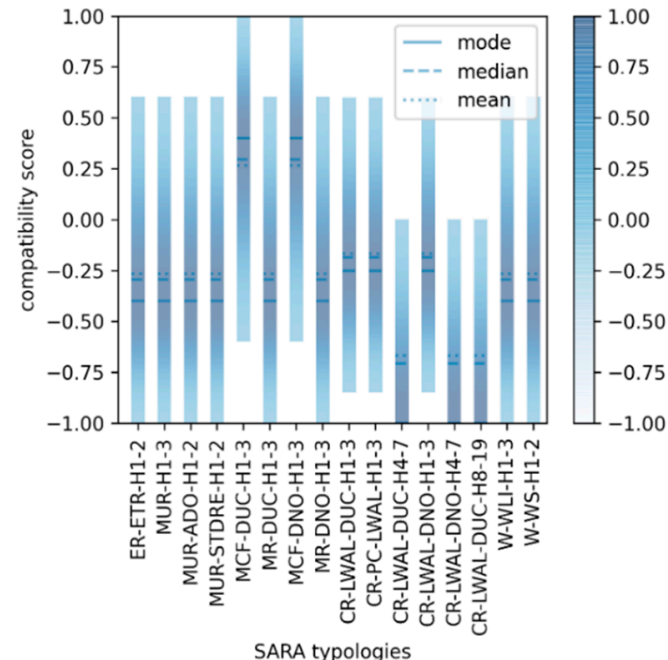

Figure A6. Resulting fuzzy compatibility scores for the building in Figure A4 with respect to the SARA typologies. The solid and dashed segments represent the equivalent defuzzified values according to the mode, median, or mean values of the triangular fuzzy numbers. 


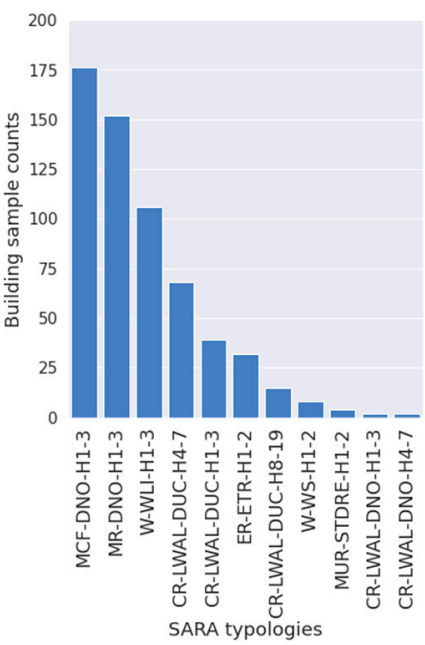

Figure A7. Distribution of the SARA typologies for the sample constituted by 604 surveyed buildings randomly distributed throughout Valparaíso (Figure A3).

\section{Appendix D. Basic Overview of the Probabilistic Exposure Modelling Approach}

In the following, we recall a Bayesian approach for exposure modelling that was initially presented in the master thesis of Zafrir (2020) [50]. This is first performed based on the probabilistic evaluation of the likelihood of observing and classifying the set of OSM footprints as one of the six building subcategories from A to F (Table 1). The obtained quantities for their enclosed SARA building classes can be obtained while keeping their underlying relation.

As in any Bayesian method, we obtained a posterior distribution that represented the composition of the building stock based on the configurations of prior and likelihood distributions. The probabilistic exposure model for the residential building stock of Valparaíso based on the OSM building footprints is given by this relation:

$$
\text { (Model } \mid \text { buildingfootprint })=\frac{\mathrm{P}(\text { building footprint } \mid \text { Model }) * \mathrm{P}(\text { Model })}{\mathrm{P}(\text { building footprint })}
$$

where $\mathrm{P}$ (Model|buildingfootprint) is the posterior distribution of the model given by the OSM building footprints, $\mathrm{P}$ (buildingfootprint|Model) is the likelihood function, $\mathrm{P}$ (Model) is the prior distribution, and $\mathrm{P}$ (Building footprint) is the observable data.

This formulation relies on the method initially suggested by Pittore et al. (2020) [39], which is grounded in statistical inference. A brief overview is presented below.

Let us consider $\mathrm{n}=\left\{\mathrm{n}_{1}, \ldots, \mathrm{n}_{\mathrm{k}}\right\}$ and $\sum_{\mathrm{k}} \mathrm{n}_{\mathrm{i}}=\mathrm{N}$ building types are observed, where $\mathrm{n}_{\mathrm{i}}$ is the number of buildings per typology $i$. The building stock can be categorised into k categories or typologies, whose frequencies are represented by a proportion $\theta=\left\{\theta_{1}, \ldots, \theta_{\mathrm{k}}\right\}, \theta_{\mathrm{i}} \geq 0$ and $\sum_{\mathrm{k}} \theta_{\mathrm{k}}=1$. A multinomial sampling model is assumed to represent the probability of observing $\mathrm{n}$, depending on $\theta$ :

$$
\mathrm{p}(\mathrm{n} \mid \theta)=\operatorname{Mul}(\mathrm{n} \mid \theta) \frac{\mathrm{N} !}{\prod_{\mathrm{i}=1}^{\mathrm{k}} \mathrm{n}_{\mathrm{i}} !} \prod_{\mathrm{i}=1}^{\mathrm{k}} \theta_{\mathrm{k}}^{\mathrm{n}_{\mathrm{i}}}
$$

Since the true proportion is unknown, $\theta_{\mathrm{i}}$ are random variables, where it is assumed that they follow a probability distribution function in the form of a Dirichlet distribution:

$$
\operatorname{Dir}(\alpha)=\frac{\Gamma\left(\sum_{\mathrm{i}=1}^{\mathrm{k}} \alpha_{\mathrm{i}}\right)}{\prod_{\mathrm{i}=1}^{\mathrm{k}} \Gamma\left(\alpha_{\mathrm{i}}\right)} \prod_{\mathrm{i}=1}^{\mathrm{k}} \theta_{\mathrm{i}}^{\alpha_{\mathrm{i}}-1}
$$

The Dirichlet distribution is parameterised by the vector $\alpha$, and it has the same number of elements $(\mathrm{k})$ as the multinomial parameter $\theta$. Thus, $\mathrm{P}(\theta \mid \alpha)$ is the interpretation of the 
question "what is the probability distribution function in a multinomial distribution $\theta$ with a Dirichlet distribution parameter $\alpha$." As a result, it can be determined how $\operatorname{Dir}(\alpha)$ varies over the values of $\theta$ for a given value of $\alpha$. By the Bayes theorem, and since the prior Dirichlet is the conjugate prior to the multinomial likelihood, the posterior probability distribution of $\theta_{\mathrm{i}}$ is also a Dirichlet distribution that is defined by the likelihood $\mathrm{p}(\mathbf{n} \mid \boldsymbol{\theta})$ and prior $\mathrm{p}(\boldsymbol{\theta})$ :

$$
\mathrm{p}(\boldsymbol{\theta} \mid \mathbf{n}) \propto \mathrm{p}(\mathbf{n} \mid \boldsymbol{\theta}) \mathrm{p}(\boldsymbol{\theta})
$$

Since both the multinomial and Dirichlet are conjugated distributions, the prior and posterior are both Dirichlet distributions that differ only by the empirical contribution of the observed data, which corresponds to the integration of OSM footprint area values. Therefore, we assumed that the observation of the OSM building footprints could be characterised through a multinomial sampling (Equation (A4)) which, when complemented with a prior composition that followed a Dirichlet distribution (Equation (A5)), could together characterise the posterior distribution. Since Dirichlet and multinomial are conjugated distributions, both the prior and posterior distributions followed a Dirichlet distribution. To apply Bayes' theorem, the mean footprint area in each grid-cell was used for the construction of the likelihood function P(building footprint I Model) from Equation (A3). We defined the function for the mean footprint model as expressed in Equation (A7):

$$
\frac{\sum_{\mathrm{i}=1}^{\mathrm{k}} \mathrm{N}_{\mathrm{b}} * \theta_{\mathrm{i}} * \mathrm{f}_{\mathrm{bi}}}{\mathrm{N}_{\mathrm{b}}}
$$

where $\mathrm{N}_{\mathrm{b}}$ is the total number of buildings in the geo-cells, $\theta_{\mathrm{i}}$ is the proportion of buildings per typology, and $\mathrm{f}_{\mathrm{bi}}$ is the footprint area per building typology. From the former expression, Equation (A8) can be derived:

$$
\sum_{i=1}^{k} \theta_{i} * f_{b i}
$$

Since $\theta$ was expected to vary from one grid cell to another, the mathematical characterisation of this variability was performed using the Dirichlet probability distribution to stochastically sample the distribution of $\theta$ in the likelihood function. Similarto what was proposed in [59], the Dirichlet hyperparameters $\alpha$ (Equation (A5)) were factorised as the product of a proportion $\left(\theta_{\mathrm{k}}\right)$ and a common (constant) concentration factor $\alpha_{\mathrm{o}}$. This was expressed as $\alpha=\theta_{\mathrm{k}} * \alpha_{\mathrm{o}}$, where $\alpha_{\mathrm{o}}$ increased the virtual counts for the category $\mathrm{k}$ and thus acted as a prior term. The larger the values of $\alpha_{0}$, the more uniform the distributions are, whilst smaller values result in sparser distributions [115]. Due to the lack of a reliable estimate about the portfolio composition, we set a low $\alpha_{0}$ value equal to 1.0. This was aligned with the decision to use uninformative priors (i.e., equal proportions for all building classes). This type of selection can be justified when there is either no particular hypothesis about the parameters that make up a given real distribution or when we have a full inventory description where all building types are equally represented [116]. It is important to note that the compositions of these types of priors will be updated after the integration of the observed data within the likelihood term (e.g., [39,59]). These data are represented by the growing data availability of OSM footprints, their observation, and their subsequent integration into the Bayesian model.

This likelihood function was used as the joint function between the observable data and the model. It computed the probability of obtaining the mean footprint area observed in the geo-cells in the calculated mean footprint area. This was equivalent to calculating the $\theta$ that maximised Equation (A3), which is given by Equation (A9):

$$
\theta=\underset{\theta}{\operatorname{argmax}}\left(\mathrm{P}(\theta \mid \mathrm{obs})=\underset{\theta}{\operatorname{argmax}}\left(\frac{\mathrm{P}(\mathrm{obs} \mid \theta) \mathrm{P}(\theta)}{\mathrm{P}(\mathrm{obs})}\right)\right.
$$

Due to the assumption of using an uninformative prior, the posterior distribution would be proportional to a maximum likelihood estimation [117]. Hence, the posterior 
distribution of the model corresponded to the maximum likelihood estimation, which is given by

$$
\theta=\underset{\theta}{\operatorname{argmax}}(\mathrm{P}(\theta \mid \text { obs })=\underset{\theta}{\operatorname{argmax}}(\mathrm{P}(\mathrm{obs} \mid \theta))
$$

where argmax over $\theta$ returns the $\theta$ value that maximises the functions in Bayes' theorem. This corresponds to asking the question "how likely will it be to observe the mean footprint area (from the geo-cell) given the $\theta$ low-rise buildings model?" The process of maximizing the likelihood function defines how probable the mean footprint area is under different values of $\theta$. Therefore, $\theta$ is a vector with values from 0 to 1 . The $\theta$ value was chosen once the likelihood was maximised. Figure A8 presents an example of this procedure. For example, as explained by [50], we can ask "what is the probability to find observed data with a mean footprint of $81 \mathrm{~m}^{2}$ (mean value in Figure A8a) in the given model?" From Figure A8b, it is possible to observe that once the likelihood term was solved for that value, it was maximised at $94 \%$. That area value was within the type of low-rise buildings, which was the value selected for such a category. Therefore, the chosen percentages for all of the observed buildings were the ones for which the likelihood function was maximised, as defined by Equation (A10).

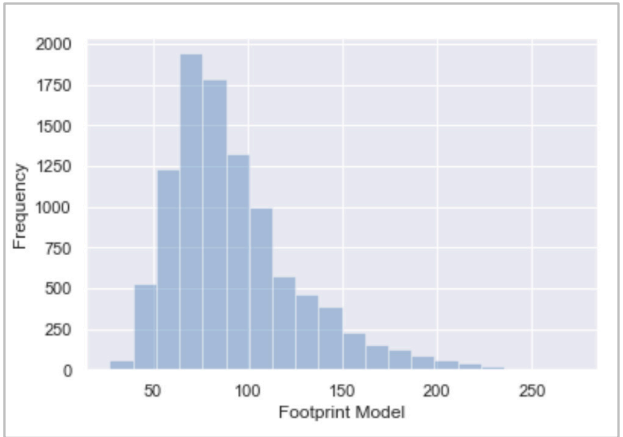

(a)

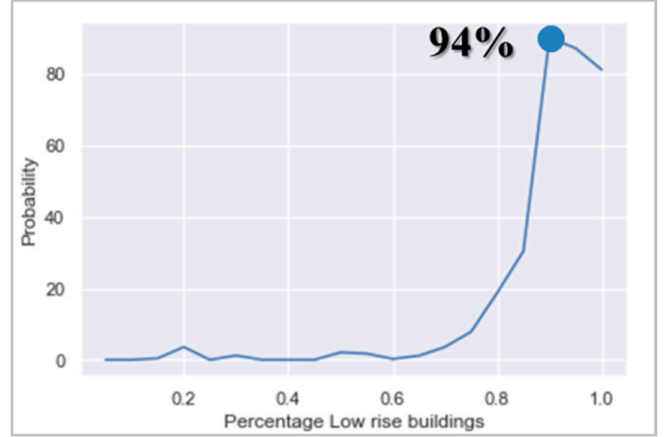

(b)

Figure A8. (a) Footprint area distribution for a given grid cell, with a mean $\sim 81 \mathrm{~m}^{2}$. (b) The posterior distribution obtained for that grid cell after having maximised the likelihood function which, in this case, was for low rise buildings. Adapted from [28].

\section{References}

1. UNISDR. UNISDR Terminology on Disaster Risk Reduction, United Nations International Strategy for Disaster Reduction; UNISDR-202009: Geneva, Switzerland, 2009.

2. Calvi, G.M.; Pinho, R.; Magenes, G.; Crowley, H.; Bommer, J.J.; Restrepo-Velez, L.F. Development of seismic vulnerability assessment methodologies over the past 30 years. ISET J. Earthq. Technol. 2006, 43, 75-104.

3. Crowley, H.; Bommer, J.J. Modelling seismic hazard in earthquake loss models with spatially distributed exposure. Bull. Earthq. Eng. 2006, 4, 275. [CrossRef]

4. Crowley, H. Earthquake risk assessment: Present shortcomings and future directions. In Perspectives on European Earthquake Engineering and Seismology: Volume 1; Ansal, A., Ed.; Springer International Publishing: Cham, Switzerland, 2014 ; pp. 515-532. ISBN 978-3-319-07118-3.

5. Corbane, C.; Hancilar, U.; Ehrlich, D.; De Groeve, T. Pan-European seismic risk assessment: A proof of concept using the earthquake loss estimation routine (ELER). Bull. Earthq. Eng. 2017, 15, 1057-1083. [CrossRef]

6. Silva, V.; Akkar, S.; Baker, J.; Bazzurro, P.; Castro, J.M.; Crowley, H.; Dolsek, M.; Galasso, C.; Lagomarsino, S.; Monteiro, R.; et al. Current challenges and future trends in analytical fragility and vulnerability modeling. Earthq. Spectra 2019, 35, 1927-1952. [CrossRef]

7. Haas, M. Towards Time- and State-Dependent Seismic Risk over Urban Scales. Ph.D. Thesis, der Technischen Universität Berlin, Berlin, Germany, 2018

8. Martins, L.; Silva, V. Development of a fragility and vulnerability model for global seismic risk analyses. Bull. Earthq. Eng. 2020. [CrossRef]

9. Jaiswal, K.; Wald, D.; Porter, K. A global building inventory for earthquake loss estimation and risk management. Earthq. Spectra 2010, 26, 731-748. [CrossRef]

10. Gunasekera, R.; Ishizawa, O.; Aubrecht, C.; Blankespoor, B.; Murray, S.; Pomonis, A.; Daniell, J. Developing an adaptive global exposure model to support the generation of country disaster risk profiles. Earth-Sci. Rev. 2015, 150, 594-608. [CrossRef] 
11. Silva, V.; Amo-Oduro, D.; Calderon, A.; Costa, C.; Dabbeek, J.; Despotaki, V.; Martins, L.; Pagani, M.; Rao, A.; Simionato, M.; et al. Development of a global seismic risk model. Earthq. Spectra 2020, 36, 372-394. [CrossRef]

12. Rao, A.; Dutta, D.; Kalita, P.; Ackerley, N.; Silva, V.; Raghunandan, M.; Ghosh, J.; Ghosh, S.; Brzev, S.; Dasgupta, K. Probabilistic seismic risk assessment of India. Earthq. Spectra 2020, 36, 345-371. [CrossRef]

13. Crowley, H.; Despotaki, V.; Rodrigues, D.; Silva, V.; Toma-Danila, D.; Riga, E.; Karatzetzou, A.; Fotopoulou, S.; Zugic, Z.; Sousa, L.; et al. Exposure model for European seismic risk assessment. Earthq. Spectra 2020, 36, 252-273. [CrossRef]

14. Ma, J.; Rao, A.; Silva, V.; Liu, K.; Wang, M. A township-level exposure model of residential buildings for mainland China. Nat. Hazards 2021, 108, 389-423. [CrossRef]

15. Xin, D.; Daniell, J.E.; Tsang, H.-H.; Wenzel, F. Residential building stock modelling for mainland China targeted for seismic risk assessment. Nat. Hazards Earth Syst. Sci. 2021, 21, 3031-3056. [CrossRef]

16. Rivera, F.; Rossetto, T.; Twigg, J. An interdisciplinary study of the seismic exposure dynamics of santiago de chile. Int. J. Disaster Risk Reduct. 2020, 48, 101581. [CrossRef]

17. Calderón, A.; Silva, V. Exposure forecasting for seismic risk estimation: Application to Costa Rica. Earthq. Spectra 2021, 37, 1806-1826. [CrossRef]

18. Yepes-Estrada, C.; Silva, V.; Valcárcel, J.; Acevedo, A.B.; Tarque, N.; Hube, M.A.; Coronel, G.; María, H.S. Modeling the residential building inventory in South America for seismic risk assessment. Earthq. Spectra 2017, 33, 299-322. [CrossRef]

19. Dabbeek, J.; Crowley, H.; Silva, V.; Weatherill, G.; Paul, N.; Nievas, C.I. Impact of exposure spatial resolution on seismic loss estimates in regional portfolios. Bull. Earthq. Eng. 2021, 19, 5819-5841. [CrossRef]

20. Wieland, M.; Pittore, M. A spatio-temporal building exposure database and information life-cycle management solution. ISPRS Int. J. Geo-Inf. 2017, 6, 114. [CrossRef]

21. Lagomarsino, S.; Giovinazzi, S. Macroseismic and mechanical models for the vulnerability and damage assessment of current buildings. Bull. Earthq. Eng. 2006, 4, 415-443. [CrossRef]

22. Wieland, M.; Pittore, M.; Parolai, S.; Zschau, J.; Moldobekov, B.; Begaliev, U. Estimating building inventory for rapid seismic vulnerability assessment: Towards an integrated approach based on multi-source imaging. Soil Dyn. Earthq. Eng. 2012, 36, 70-83. [CrossRef]

23. Riedel, I.; Guéguen, P.; Dalla Mura, M.; Pathier, E.; Leduc, T.; Chanussot, J. Seismic vulnerability assessment of urban environments in moderate-to-low seismic hazard regions using association rule learning and support vector machine methods. Nat. Hazards 2015, 76, 1111-1141. [CrossRef]

24. Liuzzi, M.; Aravena Pelizari, P.; Geiß, C.; Masi, A.; Tramutoli, V.; Taubenböck, H. A Transferable remote sensing approach to classify building structural types for seismic risk analyses: The case of val d'agri area (Italy). Bull. Earthq. Eng. 2019, 17, 4825-4853. [CrossRef]

25. Torres, Y.; Arranz, J.J.; Gaspar-Escribano, J.M.; Haghi, A.; Martínez-Cuevas, S.; Benito, B.; Ojeda, J.C. Integration of LiDAR and multispectral images for rapid exposure and earthquake vulnerability estimation. Application in Lorca, Spain. Int. J. Appl. Earth Obs. Geoinf. 2019, 81, 161-175. [CrossRef]

26. Aravena Pelizari, P.; Geiß, C.; Aguirre, P.; María, H.S.; Peña, Y.M.; Taubenböck, H. Automated building characterization for seismic risk assessment using street-level imagery and deep learning. ISPRS J. Photogramm. Remote Sens. 2021, 180, 370-386. [CrossRef]

27. Rueda-Plata, D.; González, D.; Acevedo, A.B.; Duque, J.C.; Ramos-Pollán, R. Use of deep learning models in street-level images to classify one-story unreinforced masonry buildings based on roof diaphragms. Build. Environ. 2021, 189, 107517. [CrossRef]

28. Geiß, C.; Thoma, M.; Pittore, M.; Wieland, M.; Dech, S.W.; Taubenbock, H. Multitask active learning for characterization of built environments with multisensor earth observation data. IEEE J. Sel. Top. Appl. Earth Obs. Remote Sens. 2017, 10, 5583-5597. [CrossRef]

29. Zafrir, R.; Pittore, M.; Gomez-Zapata, J.C.; Aravena, P.; Geiß, C. Bayesian downscaling of building exposure models with remote sensing and ancillary information. In Proceedings of the EGU General Assembly Conference Abstracts, Online. 4-8 May 2020; p. 18240.

30. Geiß, C.; Aravena Pelizari, P.; Priesmeier, P.; Calderon, A.R.S.; Schoepfer, E.; Langbein, M.; Riedlinger, T.; Santa María, H.; Gómez Zapata, J.C.; Pittore, M.; et al. Earth observation techniques for spatial disaggregation of exposure data. In Proceedings of the EGU General Assembly Conference Abstracts, Online. 19-30 April 2021; p. EGU21-8574.

31. Pittore, M.; Wieland, M.; Errize, M.; Kariptas, C.; Güngör, I. Improving post-earthquake insurance claim management: A novel approach to prioritize geospatial data collection. ISPRS Int. J. Geo-Inf. 2015, 4, 2401-2427. [CrossRef]

32. Pittore, M.; Wieland, M.; Fleming, K. Perspectives on global dynamic exposure modelling for geo-risk assessment. Nat. Hazards 2017, 86, 7-30. [CrossRef]

33. Brzev, S.; Scawthor, C.; Charleson, A.W.; Allen, L.; Greene, M.; Jaiswal, K.; Silva, V. GEM Building Taxonomy Version 2.0; GEM Foundation: Pavia, Italy, 2013.

34. Pittore, M.; Haas, M.; Megalooikonomou, K.G. Risk-oriented, bottom-up modeling of building portfolios with faceted taxonomies Front. Built Environ. 2018, 4, 41. [CrossRef]

35. Nicodemo, G.; Pittore, M.; Masi, A.; Manfredi, V. Modelling exposure and vulnerability from post-earthquake survey data with risk-oriented taxonomies: AeDES form, GEM taxonomy and EMS-98 typologies. Int. J. Disaster Risk Reduct. 2020, 50, 101894. [CrossRef] 
36. Shinde, S.; Gomez-Zapata, J.C.; Pittore, M.; Arroyo, O.; Merino-Peña, Y.; Aguirre, P.; Santa María, H. Development of multi-hazard exposure models from individual building observations for multi-risk assessment purposes. In Proceedings of the EGU General Assembly Conference Abstracts, Online. 4-8 May 2020; p. 11719.

37. Polese, M.; d'Aragona, M.G.; Prota, A. Simplified approach for building inventory and seismic damage assessment at the territorial scale: An application for a town in Southern Italy. Soil Dyn. Earthq. Eng. 2019, 121, 405-420. [CrossRef]

38. Kechidi, S.; Castro, J.M.; Monteiro, R.; Marques, M.; Yelles, K.; Bourahla, N.; Hamdache, M. Development of exposure datasets for earthquake damage and risk modelling: The case study of Northern Algeria. Bull. Earthq. Eng. 2021, 19, 5253-5283. [CrossRef]

39. Tocchi, G.; Polese, M.; Di Ludovico, M.; Prota, A. Regional based exposure models to account for local building typologies. Bull. Earthq. Eng. 2021, 20, 193-228. [CrossRef]

40. Pittore, M.; Haas, M.; Silva, V. Variable resolution probabilistic modeling of residential exposure and vulnerability for risk applications. Earthq. Spectra 2020, 36, 321-344. [CrossRef]

41. Hecht, R.; Kunze, C.; Hahmann, S. Measuring completeness of building footprints in openstreetmap over space and time. ISPRS Int. J. Geo-Inf. 2013, 2, 1066-1091. [CrossRef]

42. Wang, S.; Zhou, Q.; Tian, Y. Understanding completeness and diversity patterns of OSM-based land-use and land-cover dataset in China. ISPRS Int. J. Geo-Inf. 2020, 9, 531. [CrossRef]

43. Feldmeyer, D.; Meisch, C.; Sauter, H.; Birkmann, J. Using OpenStreetMap data and machine learning to generate socio-economic indicators. ISPRS Int. J. Geo-Inf. 2020, 9, 498. [CrossRef]

44. Sousa, L.; Silva, V.; Bazzurro, P. Using open-access data in the development of exposure data sets of industrial buildings for earthquake risk modeling. Earthq. Spectra 2017, 33, 63-84. [CrossRef]

45. Tumurbaatar, Z.; Miura, H.; Tsamba, T. Development of building inventory data in ulaanbaatar, mongolia for seismic loss estimation. ISPRS Int. J. Geo-Inf. 2022, 11, 26. [CrossRef]

46. Nievas, C.I.; Pilz, M.; Prehn, K.; Schorlemmer, D.; Weatherill, G.; Cotton, F. Calculating earthquake damage building by building: The case of the city of Cologne, Germany. Bull. Earthq. Eng. 2022. [CrossRef]

47. Figueiredo, R.; Martina, M. Using open building data in the development of exposure data sets for catastrophe risk modelling. Nat. Hazards Earth Syst. Sci. 2016, 16, 417-429. [CrossRef]

48. Cerri, M.; Steinhausen, M.; Kreibich, H.; Schröter, K. Are OpenStreetMap building data useful for flood vulnerability modelling? Nat. Hazards Earth Syst. Sci. 2021, 21, 643-662. [CrossRef]

49. Soman, S.; Beukes, A.; Nederhood, C.; Marchio, N.; Bettencourt, L.M.A. Worldwide detection of informal settlements via topological analysis of crowdsourced digital maps. ISPRS Int. J. Geo-Inf. 2020, 9, 685. [CrossRef]

50. Schorlemmer, D.; Beutin, T.; Cotton, F.; Garcia Ospina, N.; Hirata, N.; Ma, K.-F.; Nievas, C.; Prehn, K.; Wyss, M. Global dynamic exposure and the OpenBuildingMap-A big-data and crowd-sourcing approach to exposure modeling. In Proceedings of the EGU General Assembly Conference Abstracts, Online. 4-8 May 2020; p. 18920.

51. Zafrir, R. Downscaling Building Exposure Models: A Probabilistic Approach Using Remote Sensing Products and Open Source Auxiliary Information; Stuttgart Technology University of Applied Sciences (Hochschule für Technik Stuttgart—HFT Stuttgart): Stuttgart, Germany, 2020.

52. INE. Base Cartográfica Censal. Alcances y Consideraciones Para el Usuario; Departamento de Demografía y Censos, Instituto Nacional de Estadísticas: Santiago, Chile, 2018.

53. Gomez-Zapata, J.C.; Pittore, M.; Cotton, F.; Lilienkamp, H.; Simantini, S.; Aguirre, P.; Hernan, S.M. Epistemic uncertainty of probabilistic building exposure compositions in scenario-based earthquake loss models. Bull. Earthq. Eng. 2022. [CrossRef]

54. Carvajal, M.; Cisternas, M.; Catalán, P.A. Source of the 1730 Chilean earthquake from historical records: Implications for the future tsunami hazard on the coast of metropolitan Chile. J. Geophys. Res. Solid Earth 2017, 122, 3648-3660. [CrossRef]

55. Montessus de Ballore, F. Historia sísmica de los Andes Meridionales al sur del paralelo XVI, Cuarta Parte; Imprenta Cervantes: Santiago, Chile, 1914.

56. Indirli, M.; Razafindrakoto, H.; Romanelli, F.; Puglisi, C.; Lanzoni, L.; Milani, E.; Munari, M.; Apablaza, S. Hazard evaluation in Valparaíso: The MAR VASTO project. Pure Appl. Geophys. 2011, 168, 543-582. [CrossRef]

57. Comte, D.; Eisenberg, A.; Lorca, E.; Pardo, M.; Ponce, L.; Saragoni, R.; Singh, S.K.; Suarez, G. The 1985 central Chile earthquake: A repeat of previous great earthquakes in the region? Science 1986, 233, 449. [CrossRef]

58. de la Llera, J.C.; Rivera, F.; Mitrani-Reiser, J.; Jünemann, R.; Fortuño, C.; Ríos, M.; Hube, M.; Santa María, H.; Cienfuegos, R. Data collection after the 2010 Maule earthquake in Chile. Bull. Earthq. Eng. 2017, 15, 555-588. [CrossRef]

59. Gómez Zapata, M.; Jiménez Martínez, M.; Romero-Jarén, R. How resilient is the labour market against natural disaster? Evaluating the effects from the 2010 earthquake in Chile. Nat. Hazards 2020, 104, 1481-1533. [CrossRef]

60. Nealy, J.L.; Herman, M.W.; Moore, G.L.; Hayes, G.P.; Benz, H.M.; Bergman, E.A.; Barrientos, S.E. 2017 Valparaíso earthquake sequence and the megathrust patchwork of central Chile. Geophys. Res. Lett. 2017, 44, 8865-8872. [CrossRef]

61. Jiménez, B.; Pelà, L.; Hurtado, M. Building survey forms for heterogeneous urban areas in seismically hazardous zones. Application to the historical center of Valparaíso, Chile. Int. J. Arch. Herit. 2018, 12, 1076-1111. [CrossRef]

62. GEM. Report on the SARA Exposure and Vulnerability Workshop in Medellin, Colombia. 2014. Available online: https: / / sara.openquake.org/_media/risk:03_2014_-_workshop_medellin_-_exposure.pdf (accessed on 21 December 2021). 
63. Geiß, C.; Schauß, A.; Riedlinger, T.; Dech, S.; Zelaya, C.; Guzmán, N.; Hube, M.A.; Arsanjani, J.J.; Taubenböck, H. Joint use of remote sensing data and volunteered geographic information for exposure estimation: Evidence from Valparaíso, Chile. Nat. Hazards 2017, 86, 81-105. [CrossRef]

64. CIESIN. Documentation for the Gridded Population of TheWorld, Version 4 (GPWv4), Revision 11 Data Sets. Available online: https:/ / doi.org/10.7927/H45Q4T5F (accessed on 21 December 2021).

65. ESA European Space Agency. Sentinel-2 MSI; European Space Agency: Paris, France, 2018.

66. ERDAS. ERDAS Imagine 2014; Hexagon Geospatial, Peachtree Corners Circle Norcross: Norcross, GA, USA, 2014.

67. Mohammadi, A.; Karimzadeh, S.; Valizadeh Kamran, K.; Matsuoka, M. Extraction of land information, future landscape changes and seismic hazard assessment: A case study of Tabriz, Iran. Sensors 2020, 20, 7010. [CrossRef]

68. INE. Censo de Población y Vivienda 2002; Instituto Nacional de Estadística de Chile: Santiago, Chile, 2002.

69. Villar-Vega, M.; Silva, V.; Crowley, H.; Yepes, C.; Tarque, N.; Acevedo, A.B.; Hube, M.A.; Gustavo, C.D.; María, H.S. Development of a fragility model for the residential building stock in South America. Earthq. Spectra 2017, 33, 581-604. [CrossRef]

70. INITN. Instituto Nacional de Investigaciones Tecnológica y Normalizaciones, Cálculo Antisísmico de Edificios, NCh.433 of 72; Technical Report; INITN: Santiago de Chile, Chile, 1972.

71. INN. Instituto Nacional de Normalización Diseño Sísmico de Edificios, NCh.433 of 96; Technical Report; INN: Santiago de Chile, Chile, 1996.

72. Dell'Acqua, F.; Gamba, P.; Jaiswal, K. Spatial aspects of building and population exposure data and their implications for global earthquake exposure modeling. Nat. Hazards 2013, 68, 1291-1309. [CrossRef]

73. Bal, I.E.; Bommer, J.J.; Stafford, P.J.; Crowley, H.; Pinho, R. The influence of geographical resolution of urban exposure data in an earthquake loss model for Istanbul. Earthq. Spectra 2010, 26, 619-634. [CrossRef]

74. Senouci, A.; Bard, P.-Y.; Beck, E.; Farsi, M.N.; Cartier, S. Mapping seismic vulnerability at urban scale: Discussion on relevant cartography representations and smoothing for urban planning purposes on the oran case study. Soil Dyn. Earthq. Eng. 2018, 115, 545-563. [CrossRef]

75. Scheingraber, C.; Käser, M. Spatial seismic hazard variation and adaptive sampling of portfolio location uncertainty in probabilistic seismic risk analysis. Nat. Hazards Earth Syst. Sci. 2020, 20, 1903-1918. [CrossRef]

76. Gomez-Zapata, J.C.; Brinckmann, N.; Harig, S.; Zafrir, R.; Pittore, M.; Cotton, F.; Babeyko, A. Variable-resolution building exposure modelling for earthquake and tsunami scenario-based risk assessment. An application case in Lima, Peru. Nat. Hazards Earth Syst. Sci. 2021, 21, 3599-3628. [CrossRef]

77. OSM Task Manager. \#502-Valparaíso, Chile Fires/Fuegos En Valparaíso, Chile. 2014. Available online: https://tasks.hotosm. org/projects/502 (accessed on 21 December 2021).

78. OSM Task Manager. \#508—Valparaíso, Chile Fires 2/Fuegos En Valparaíso, Chile. 2014. Available online: https://tasks.hotosm. org/projects/508 (accessed on 21 December 2021).

79. Reszka, P.; Fuentes, A. The great valparaiso fire and fire safety management in Chile. Fire Technol. 2015, 51, 753-758. [CrossRef]

80. Haas, M.; Wieland, M.; Pittore, M. DEMO: Remote Rapid Visual Screening (RRVS). Available online: https://vimeo.com/158600 573 (accessed on 21 December 2021).

81. Merino-Peña, Y.; Pittore, M.; Gomez-Zapata, J.C. RRVS building survey for building exposure modelling in valparaiso and viña del mar (Chile). V. 1.0. GFZ Data Serv. 2021. [CrossRef]

82. Acevedo, A.B.; Jaramillo, J.D.; Yepes, C.; Silva, V.; Osorio, F.A.; Villar, M. Evaluation of the seismic risk of the unreinforced masonry building stock in Antioquia, Colombia. Nat. Hazards 2017, 86, 31-54. [CrossRef]

83. Arroyo, O.; Feliciano, D.; Carrillo, J.; Hube, M.A. Seismic performance of mid-rise thin concrete wall buildings lightly reinforced with deformed bars or welded wire mesh. Eng. Struct. 2021, 241, 112455. [CrossRef]

84. Vásquez, J.A.; Jünemann, R.; de la Llera, J.C.; Hube, M.A.; Chacón, M.F. Three-dimensional nonlinear response history analyses for earthquake damage assessment: A reinforced concrete wall building case study. Earthq. Spectra 2021, 37, 235-261. [CrossRef]

85. Weatherill, G.; Pittore, M.; Haas, M.; Brinckmann, N.; Rüster, M.; Gomez-Zapata, J.C. Shakyground: A web service to serve GMPE-based ground motion fields. V. 1.0. GFZ Data Serv. 2021. [CrossRef]

86. Pagani, M.; Monelli, D.; Weatherill, G.; Danciu, L.; Crowley, H.; Silva, V.; Henshaw, P.; Butler, L.; Nastasi, M.; Panzeri, L.; et al. OpenQuake engine: An open hazard (and risk) software for the global earthquake model. Seism. Res. Lett. 2014, 85, 692-702. [CrossRef]

87. Kalakonas, P.; Silva, V.; Mouyiannou, A.; Rao, A. Exploring the impact of epistemic uncertainty on a regional probabilistic seismic risk assessment model. Nat. Hazards 2020, 104, 997-1020. [CrossRef]

88. Kotha, S.R.; Bazzurro, P.; Pagani, M. Effects of epistemic uncertainty in seismic hazard estimates on building portfolio losses. Earthq. Spectra 2018, 34, 217-236. [CrossRef]

89. Hussain, E.; Elliott, J.R.; Silva, V.; Vilar-Vega, M.; Kane, D. Contrasting seismic risk for Santiago, Chile, from near-field and distant earthquake sources. Nat. Hazards Earth Syst. Sci. 2020, 20, 1533-1555. [CrossRef]

90. Ghofrani, H.; Atkinson, G.M. Ground-motion prediction equations for interface earthquakes of M7 to M9 based on empirical data from Japan. Bull. Earthq. Eng. 2014, 12, 549-571. [CrossRef]

91. Abrahamson, N.; Gregor, N.; Addo, K. BC hydro ground motion prediction equations for subduction earthquakes. Earthq. Spectra 2016, 32, 23-44. [CrossRef] 
92. Montalva, G.A.; Bastías, N.; Rodriguez-Marek, A. Ground-motion prediction equation for the chilean subduction zone. Bull. Seism. Soc. Am. 2017, 107, 901-911. [CrossRef]

93. Peyghaleh, E.; Mahmoudabadi, V.; Martin, J.R.; Shahjouei, A.; Chen, Q.; Javanbarg, M.; Khoshnevisan, S. Impact of local site conditions on portfolio earthquake loss estimation for different building types. Nat. Hazards 2018, 94, 121-150. [CrossRef]

94. Heath, D.C.; Wald, D.J.; Worden, C.B.; Thompson, E.M.; Smoczyk, G.M. A global hybrid VS30 map with a topographic slope-Based default and regional map insets. Earthq. Spectra 2020, 36, 1570-1584. [CrossRef]

95. Mendoza, L.; Ayala, F.; Fuentes, B.; Soto, V.; Sáez, E.; Yañez, G.; Montalva, G.; Gález, C.; Sepúlveda, N.; Lazo, I.; et al. Estimación Cuantitativa de la Amenaza Sísmica en Base a Métodos Geofísicos: Aplicación a las Localidades Costeras del Segmento los Vilos-San Antonio; Congreso SOCHIGE: Valparaiso, Chile, 2018.

96. Weatherill, G.A.; Silva, V.; Crowley, H.; Bazzurro, P. Exploring the impact of spatial correlations and uncertainties for portfolio analysis in probabilistic seismic loss estimation. Bull. Earthq. Eng. 2015, 13, 957-981. [CrossRef]

97. Jayaram, N.; Baker, J.W. Correlation model for spatially distributed ground-motion intensities. Earthq. Eng. Struct. Dyn. 2009, 38, 1687-1708. [CrossRef]

98. Markhvida, M.; Ceferino, L.; Baker, J.W. Modeling spatially correlated spectral accelerations at multiple periods using principal component analysis and geostatistics. Earthq. Eng. Struct. Dyn. 2018, 47, 1107-1123. [CrossRef]

99. Silva, V. Critical issues in earthquake scenario loss modeling. J. Earthq. Eng. 2016, 20, 1322-1341. [CrossRef]

100. Pittore, M.; Gomez-Zapata, J.C.; Brinckmann, N.; Rüster, M. Assetmaster and modelprop: Web services to serve building exposure models and fragility functions for physical vulnerability to natural-hazards. V. 1.0. GFZ Data Serv. 2021. [CrossRef]

101. Brinckmann, N.; Gomez-Zapata, J.C.; Pittore, M.; Rüster, M. DEUS: Damage-exposure-update-service. V. 1.0. GFZ Data Serv. 2021. [CrossRef]

102. Beven, K.J.; Aspinall, W.P.; Bates, P.D.; Borgomeo, E.; Goda, K.; Hall, J.W.; Page, T.; Phillips, J.C.; Simpson, M.; Smith, P.J.; et al. Epistemic uncertainties and natural hazard risk assessment-Part 2: What should constitute good practice? Nat. Hazards Earth Syst. Sci. 2018, 18, 2769-2783. [CrossRef]

103. Vamvatsikos, D.; Panagopoulos, G.; Kappos, A.J.; Nigro, E.; Rossetto, T.; Lloyd, T.O.; Stathopoulos, T. Structural vulnerability assessment under natural hazards: A review. In Urban Habitat Constructions under Catastrophic Events; Chapter 3-4; Mazzolani, F.M., Ed.; CRC Press: Boca Raton, FL, USA, 2010.

104. Stafford, P.J. Evaluation of structural performance in the immediate aftermath of an earthquake: A case study of the 2011 christchurch earthquake. Int. J. Forensic Eng. 2012, 1, 58-77. [CrossRef]

105. Aguirre, P.; Vásquez, J.; de la Llera, J.C.; González, J.; González, G. Earthquake damage assessment for deterministic scenarios in Iquique, Chile. Nat. Hazards 2018, 92, 1433-1461. [CrossRef]

106. Zuccaro, G.; De Gregorio, D.; Leone, M.F. Theoretical model for cascading effects analyses. Int. J. Disaster Risk Reduct. 2018, 30, 199-215. [CrossRef]

107. Pilz, M.; Cotton, F. Does the one-dimensional assumption hold for site response analysis? A study of seismic site responses and implication for ground motion assessment using KiK-Net strong-motion data. Earthq. Spectra 2019, 35, 883-905. [CrossRef]

108. Candia, G.; Poulos, A.; de la Llera, J.C.; Crempien, J.G.F.; Macedo, J. Correlations of spectral accelerations in the Chilean subduction zone. Earthq. Spectra 2020, 36, 788-805. [CrossRef]

109. Abbasnejadfard, M.; Bastami, M.; Fallah, A.; Garakaninezhad, A. Analyzing the effect of anisotropic spatial correlations of earthquake intensity measures on the result of seismic risk and resilience assessment of the portfolio of buildings and infrastructure systems. Bull. Earthq. Eng. 2021, 19, 5791-5817. [CrossRef]

110. Cabrera, T.; Hube, M.; Santa María, H. Empirical fragility curves for reinforced concrete and timber houses, using different intensity measures. In Proceedings of the 17th World Conference on Earthquake Engineering, Sendai, Japan, 13-18 September 2020.

111. Sousa, L.; Silva, V.; Marques, M.; Crowley, H. On the treatment of uncertainty in seismic vulnerability and portfolio risk assessment. Earthq. Eng. Struct. Dyn. 2018, 47, 87-104. [CrossRef]

112. Pittore, M.; Graziani, L.; Maramai, A.; Haas, M.; Parolai, S.; Tertulliani, A. Bayesian estimation of macroseismic intensity from post-earthquake rapid damage mapping. Earthq. Spectra 2018, 34, 1809-1828. [CrossRef]

113. Contreras, D.; Wilkinson, S.; James, P. Earthquake reconnaissance data sources, a literature review. Earth 2021, 2, $1006-1037$. [CrossRef]

114. Gomez-Zapata, J.C.; Shinde, S.; Pittore, M.; Merino-Peña, Y. Scripts to generate (1) Attribute-based fuzzy scores for SARA and HAZUS building classes, and (2) Probabilistic inter-scheme compatibility matrices. An application on the residential building stock of Valparaiso (Chile) for seismic risk applications. GFZ Data Serv. 2021. [CrossRef]

115. Xing, E.P. 19: Bayesian Nonparametrics: Dirichlet Processes. Probabilistic Graphical Models 10-708. 2014. Available online: https:/ / www.cs.cmu.edu/ \{\}epxing/Class/10708-14/scribe_notes/scribe_note_lecture19.pdf (accessed on 21 December 2021).

116. Pittore, M.; Wieland, M. Toward a rapid probabilistic seismic vulnerability assessment using satellite and ground-based remote sensing. Nat. Hazards 2013, 68, 115-145. [CrossRef]

117. Lynch, S.M. Introduction to Applied Bayesian Statistics and Estimation for Social Scientists; Springer: New York, NY, USA, 2007; ISBN 978-0-387-71264-2. 